\title{
Endophytes from Ginkgo biloba and their secondary metabolites
}

\author{
Zhihui Yuan ${ }^{1,3}$, Yun Tian' ${ }^{1}$, Fulin He 2,3* $^{*}$ and Haiyan Zhou ${ }^{1 *}$ (C)
}

\begin{abstract}
Ginkgo biloba is a medicinal plant which contains abundant endophytes and various secondary metabolites. According to the literary about the information of endophytics from Ginkgo biloba, Chaetomium, Aspergillus, Alternaria, Penicillium and Charobacter were isolated from the root, stem, leaf, seed and bark of G. biloba. The endophytics could produce lots of phytochemicals like flavonoids, terpenoids, and other compounds. These compounds have antibacteria, antioxidation, anticardiovascular, anticancer, antimicrobial and some novel functions. This paper set forth the development of active extracts isolated from endophytes of Ginkgo biloba and will help to improve the resources of Ginkgo biloba to be used in a broader field.
\end{abstract}

Keywords: Ginkgo biloba, Chinese medical plant, Endophytes, Secondary metabolites

\section{Background}

Ginkgo biloba (G. biloba) is a deciduous tree belonging to the ginkgo genus, which is also known as Gongsunshu, etc. G. biloba is one of the most ancient plants on earth dating back more than 200 million years. Commonly Ginkgo biloba has been used for a medicinal plant and its seeds, leaves and fruits can be used for medicines with biological activities involving antibacteria, antioxidation, anticardiovascular and others. However, Ginkgo trees grow slowly and under natural conditions they need more than 20 years from planting to fruiting, which is a restricting point for its development; while its endophytics provide physiological metabolic pathways to produce numerous novel medicinal compounds which have become a hotspot [1].

The endophytics play important roles in the process of host plant growth and systematic evolution [1, 2]. During the whole life, endophytics protect their host from infectious diseases and also help to survive in adverse environment [3]. Since the unique relationships between the host plant and associated endophytes, endophytes in G. biloba

\footnotetext{
*Correspondence: hefulin0012@163.com; haiyanzhou1204@hotmail.com ${ }^{1}$ College of Bioscience and Biotechnology, Hunan Agricultural University, Changsha 410128, China

${ }^{3}$ College of Chemistry and Bioengineering, Hunan University of Science and Engineering, Yongzhou 425199, China

Full list of author information is available at the end of the article
}

have been recognized as important sources of a variety of novel secondary metabolites with anticancer, antimicrobial and other biological activities $[4,5]$.

Secondary metabolites are the chemical bank which provides a huge quantity of diverse commercial products for human medicines. First report about endophytics is that Stierle et al. isolated Taxomyces andreanae from phloem of Taxus brevifolia, which can produce taxol and related chemicals at the concentration of 24-50 $\mathrm{ng} / \mathrm{L}$ [6]. From then on, more and more endophytics from pharmaceutical plants, such as Camptotheca acuminata [7], pine [8] and Taxus plants [9-11] were isolated. As to G. biloba, various endophytics including Chaetomium, Aspergillus, Alternaria, Penicillium and Charobacter were isolated from the root, stem, leaf, seed and bark of G. biloba. They produce lots of phytochemicals like flavonoids, terpenoids, and other compounds [12,13]. 50\% of these isolates showed antimicrobial activities against various pathogens. Some secondary metabolites such as 2-hexenal have been involved in the plant's defense against pests. These bioactive metabolites are attractive to developing the commercial prodrugs and agricultural/ industrial production. Most importantly, as a therapeutic drug, G. biloba has no side effects even after long periods of use and its phytopharmaceuticals are readily accessible throughout the world. For better using endophytic and

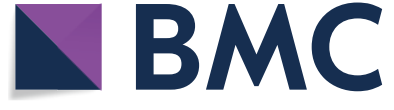

(c) The Author(s) 2019. This article is distributed under the terms of the Creative Commons Attribution 4.0 International License (http://creativecommons.org/licenses/by/4.0/), which permits unrestricted use, distribution, and reproduction in any medium, provided you give appropriate credit to the original author(s) and the source, provide a link to the Creative Commons license, and indicate if changes were made. The Creative Commons Public Domain Dedication waiver (http://creativecommons.org/ publicdomain/zero/1.0/) applies to the data made available in this article, unless otherwise stated. 
secondary metabolites from ginkgo trees, we summarize the data previously reported.

\section{Endophytes in Ginkgo biloba}

The whole plant of G. biloba can be used as medicine. In its root, stem, leaf, seed and bark of Ginkgo biloba, various endophytes have been isolated and their biological function was investigated. The conventional procedure of endophytes isolation is to wash the roots, stems or leaves of ginkgo firstly with $75 \%$ alcohol for $3 \mathrm{~min}$, rinse with sterile water $3-5$ times, $0.1 \%$ mercury sterilized for $2 \mathrm{~min}$, rinsed with sterile water 3-5 times, cut into $0.5 \mathrm{~cm} \times 0.5 \mathrm{~cm}$ pieces. The cutting pieces were inoculated in PDA medium at $28{ }^{\circ} \mathrm{C}$ for 4 days. After purification, ginkgo endophytes were isolated.

For the endophytic procaryotes, on the total DNA as the template, 27F(AGAGTTTGATC-CTGGGT CAG)/1492R(GGTTACCTTGTTACGACTT) as a primer, $16 \mathrm{~S}$ rDNA was amplified. For the endophytic eukarya, ITS5 (GAAG TAAAAG TCGTAACAAGG)/ ITS4 (TCCTCCGC TTA TTGA TATGC) as a primer, ITS rDNA was amplified. According to the culturing and molecular analysis between different species, the endophytics residing in G. biloba belong to Chaetomium, Aspergillus, Alternaria, Penicillium, Charobacter, etc.

\section{Endophytic procaryotes in Ginkgo biloba}

From the previous reports, around 50 species of endophytic procaryotes were found including Bacillus subtilis, Lactobacillus sp., Fusobacterium sp., Gemella sp., Neisseria sp., Pseudomonas sp., Rothia sp., Veillonella sp., etc. Basing on 16S RNA sequence of endophytic procaryotes from previous literatures, the phylogenetic tree was constructed in Fig. 1. Amongst these procaryotes, the community structure or compositional differences at different taxonomic levels was presented in Fig. 2.

Sphingomonadaceae are a family of the Alphaproteobacteria and most abundant in G. biloba. An important feature is the presence of sphingolipids in the outer membrane of the cell wall [14]. In this family, some species are phototrophic which may have high nutritional value. The phototrophic bacteria are rich in amino acids, folic acid and vitamins, especially vitamin B12, biotin and coenzyme Q. Some other species are known as the ability to degrade some aromatic compounds which has the interests for environmental remediation [11].

Other abundant species are family Hyphomicrobiaceae, Burkholderiaceae, Methylobacteriaceae, Enterobacteriaceae, Neisseriaceae and Micrococcaceae. The family Hyphomicrobiaceae is affiliated with Alphaproteobacteria and members of this family are distributed everywhere in soils, freshwater, and also under the marine. This family is highly diverse morphologically and physiologically.
Most are aerobic chemoheterotrophs and a few can grow anaerobically by denitrification or mixed-acid fermentation.

The Methylobacteriaceae comprises a large family of Alphaproteobacteria and contains three genera including Methylobacterium, Microvirga, and Meganema. Methylobacterium species are ubiquitous in the natural environment. Some species induce plant leaf and root nodule formation, and can promote plant growth by production of auxins [15]. Most of Methylobacterium are methylotrophs and they can use methanol or other one-carbon compounds as energy sources to produce proteins [16]. Otherwise, in Methylobacterium, common fatty acids were contained especially ubiquinone Q-10, a popular dietary supplement.

Family Enterobacteriaceae contains a large number of genera that are biochemically and genetically related to one another. Many of them are pathogens, such as Salmonella, Shigella or Yersinia, because they produce endotoxins. Endotoxins reside in the cell wall and when the cell dies and the cell wall disintegrates, endotoxins are released [9].

Family Burkholderiaceae belongs to the order Burkholderiales within the class Betaproteobacteria. This family is characterized by the presence of ecologically extremely diverse organisms and contains truly environmental saprophytic organisms, phytopathogens, opportunistic pathogens, as well as primary pathogens for humans and animals.

Family Neisseriaceae and Micrococcaceae are widespread in soil, subterranean cave silts, sea, glacier silts, sewage, water sludge, aerial surfaces of plants, vegetables, and various animal species and are even more distantly related to the human pathogens.

\section{Endophytic eukarya in Ginkgo biloba}

The phylogenetic tree of endophytic eukarya (Fig. 3) was constructed basing on ITS sequence of roots and leaves of Ginkgo biloba from previous literatures. Amongst these endophytic eukarya, the community structure at different taxonomic levels was presented in Fig. 4.

Amongst eukarya, family Pleosporaceae belongs to sac fungi. The taxonomic relationship of this family to associated genera is still not determined. The classification of Pleosporaceae has been a challenge because of the lack of the importance of morphological characters and reference strains. From the present knowledge, the family Pleosporaceae includes numerous saprobic, opportunistic human and plant pathogenic taxa [17].

Phaeosphaeriaceae is a large and important family of fungi in the order Pleosporales. Species in this family have a cosmopolitan distribution, and are generally 


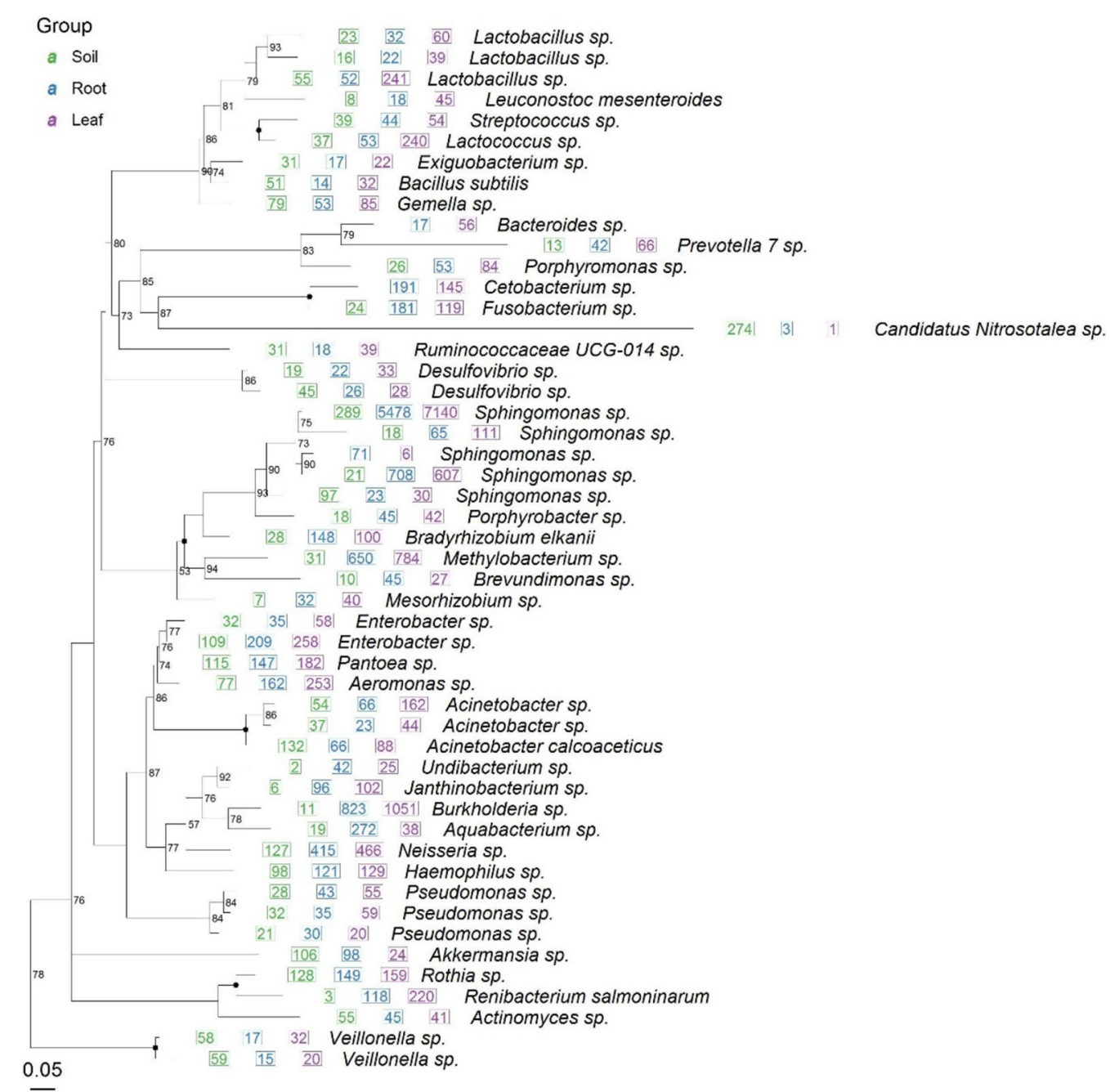

Fig. 1 The phylogenetic tree of endophytic procaryotes from soil, root and leaf of Ginkgo biloba. 50 most abundant OTUs are used for display. If a number appears before the species name, it represents the total number of sequences of this OTU. If it is a graph, the graph size represents the relative abundance (percentage), and the black dot on the branch represents the bootstrap confidence greater than 95\%

nectrotrophic or saprobic on a wide range of plants [18]. This family includes economically important plant pathogens and previously accommodated 35 sexual and asexual genera and comprised more than 300 species with a range of morphological characters [19].

The Xylariaceae are a family of mostly small ascomycetous fungi. It is one of the most commonly encountered groups of ascomycetes and is found throughout the temperate and tropical regions of the world. They are typically found on wood, seeds, fruits, or plant leaves, some even associated with insect nests. Most decay wood and many are plant pathogens. Phylogenetic analyses suggest that there are two main lineages in this family, Hypoxyloideae and Xylarioideae [20, 21].

\section{Secondary metabolites of endophytics in Ginkgo biloba}

A series of compounds were obtained by fermentation, extraction, and isolation from endophytics of G. biloba, amongst which 115 metabolites were found in the fermentation broth of Chaetomium fungi, 44 metabolites were found from Aspergillus, 43 metabolites found in the genus Xylaria. The amount from these three genera accounted for $72 \%$ of the secondary metabolites from endophytic procaryotes and $21 \%$ were isolated from Fusarium, Alternaria and Penicillium. The number of metabolites of each genus is shown in Fig. 5.

Many metabolic products from G. biloba have strong inhibitory effects on pathogenic bacteria Staphylococcus 

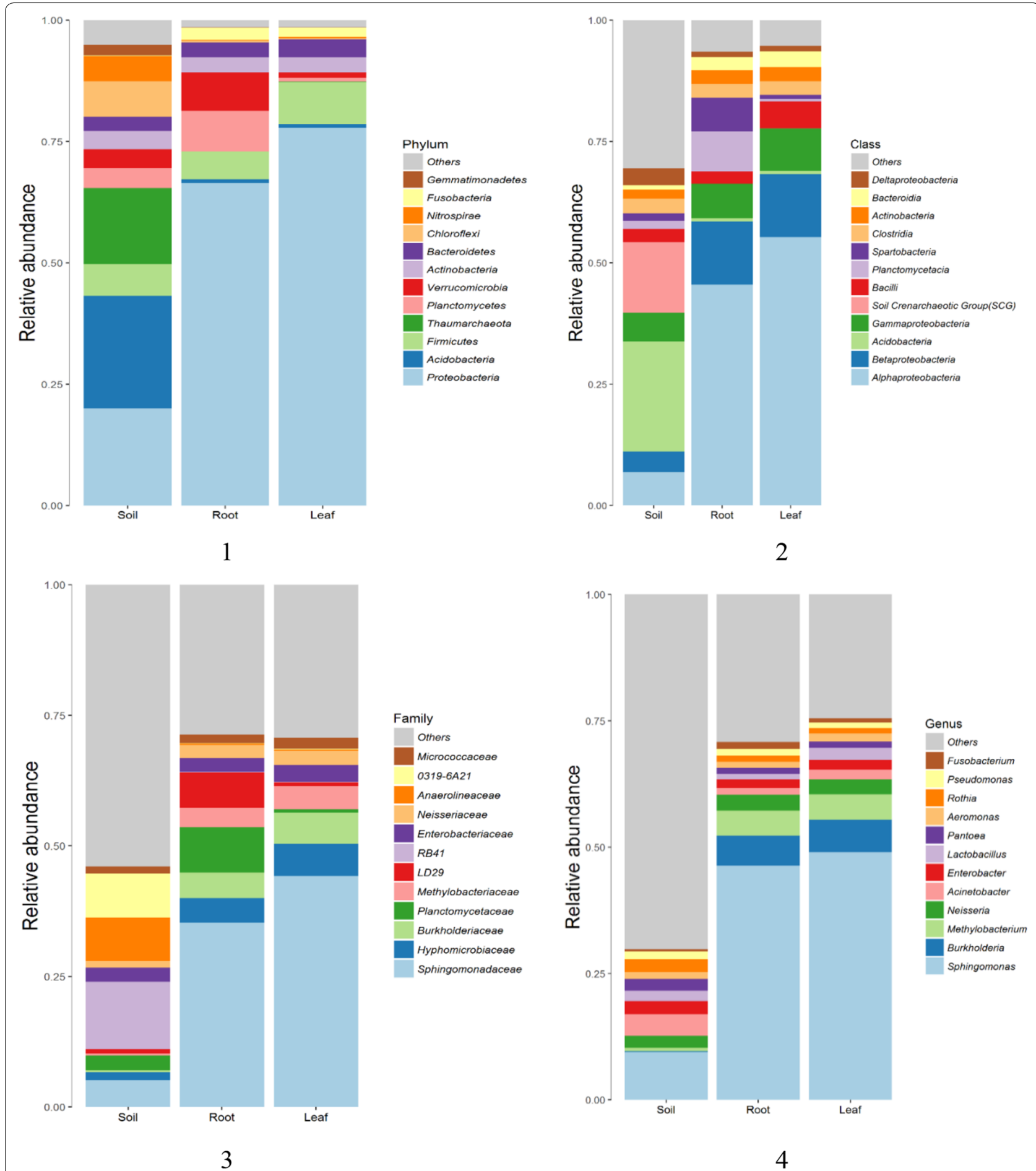

Fig. 2 The community structure at different taxonomic levels. (1) The community structure at different phylums; (2) the community structure at different classes; (3) the community structure at different families; (4) the community structure at different genus. The percentage in parentheses indicates that only the group with the average abundance greater than this ratio is listed. All other groups are classified in others

aureus, Enterococcus faecalis, and Pseudomonas aeruginosa. The secondary metabolites of Ginkgo, such as flavonoids and ginkgolides, are drugs or prodrugs used in the treatment of peripheral arterial diseases, neurological disorders, sclerosis of cerebral arteries, and cerebral ageing. 


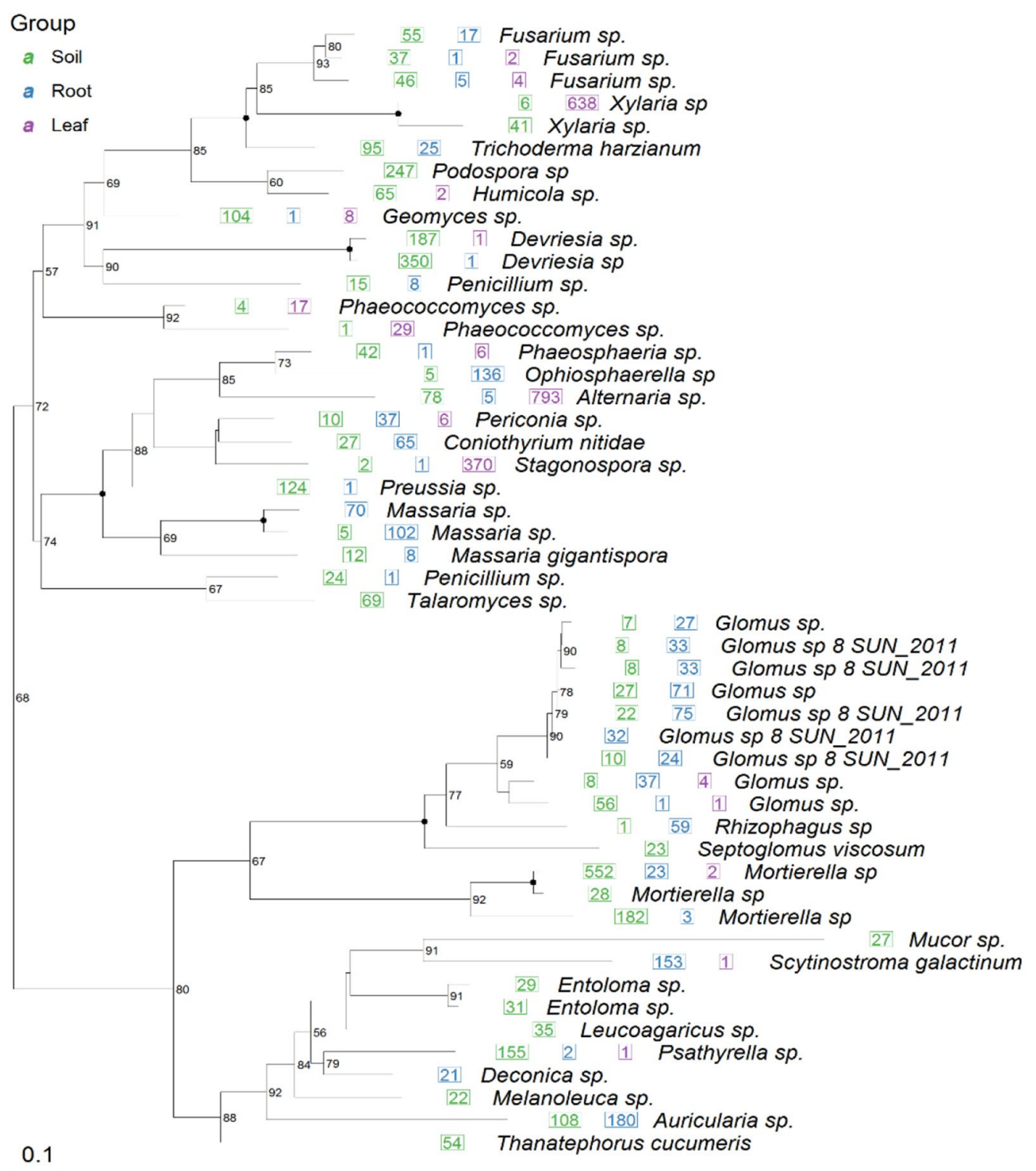

Fig. 3 The phylogenetic tree of endophytic eukarya from soil, root and leaf of Ginkgo biloba. 50 most abundant OTUs are used for display. If a number appears before the species name, it represents the total number of sequences of this OTU. If it is a graph, the graph size represents the relative abundance (percentage), and the black dot on the branch represents the bootstrap confidence greater than $95 \%$

\section{Secondary metabolites of Chaetomium}

Chaetomium is the largest type of endophytic fungus from G. biloba and its secondary metabolites are biologically diverse. Chaetomium globosum is one of main endophytics. A total of 115 metabolites were isolated from the fermentation broth of Chaetomium globosum (see Fig. 6 and Table 1). Among them, chaetoglobosin $\mathrm{A}$, chaetoglobosin $\mathrm{C}$, chaetoglobosin $\mathrm{E}$, chaetoglobo$\sin \mathrm{G}$, chaetoglobosin $\mathrm{Vb}$, chaetomugilin $\mathrm{A}$, chaetomugilin D and ergosterol peroxide (peroxyergosterol; $5 \alpha$,
$8 \alpha$-peroxy-(22E, 24R)-ergot-6,22-diene-3 $\beta$-ol), which has been reported in many literatures, may be a research hotspot. Among these compounds, chaetomugilin A, chaetomugilin D, chaetoglobosin A and chaetoglobosin $\mathrm{C}$ have strong cytotoxic activity [22].

Chaetomugilin A and D, both are a kind of azaphilone isolated from Chaetomium globosum and has been shown to exhibit inhibitory activity against the brine shrimp (Artemia salina) and Mucor miehei [22]. Chaetomugilide A isolated from Chaetomium globosum 

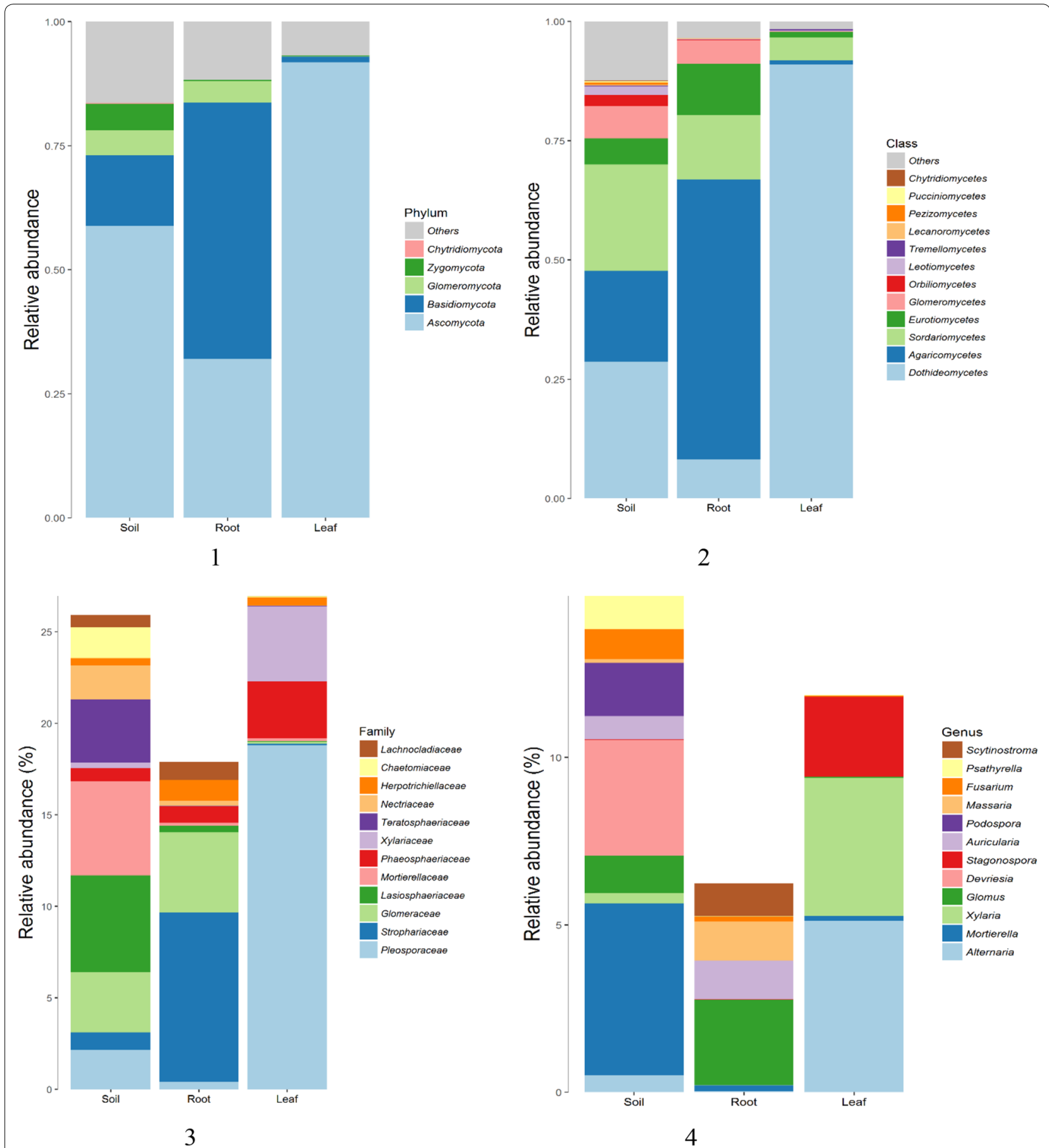

Fig. 4 The community structure at different taxonomic levels. (1) The community structure at different phylums; (2) The community structure at different classes; (3) The community structure at different families; (4) the community structure at different genus. The percentage in parentheses indicates that only the group with the average abundance greater than this ratio is listed. All other groups are classified in others

TY1 has strong activity against hepatoma cell HepG-2, and the $\mathrm{IC}_{50}$ value is only $1.7 \mu \mathrm{mol} / \mathrm{L}$ [23]. Chaetoglobosin $\mathrm{A}$ is a Chaetomium secretion with the anticancer activity in vitro [24] and it derivates into other bilobalide compounds MBJ-0038, MBJ-0039, and MBJ-0040 [25]. Chaetoglobosin $\mathrm{E}$ is a cytochalasan alkaloid found in Chaetomium globosum and Chaetomium subaffine. It is a cytochalasan alkaloid, a member of indoles, a macrocycle 


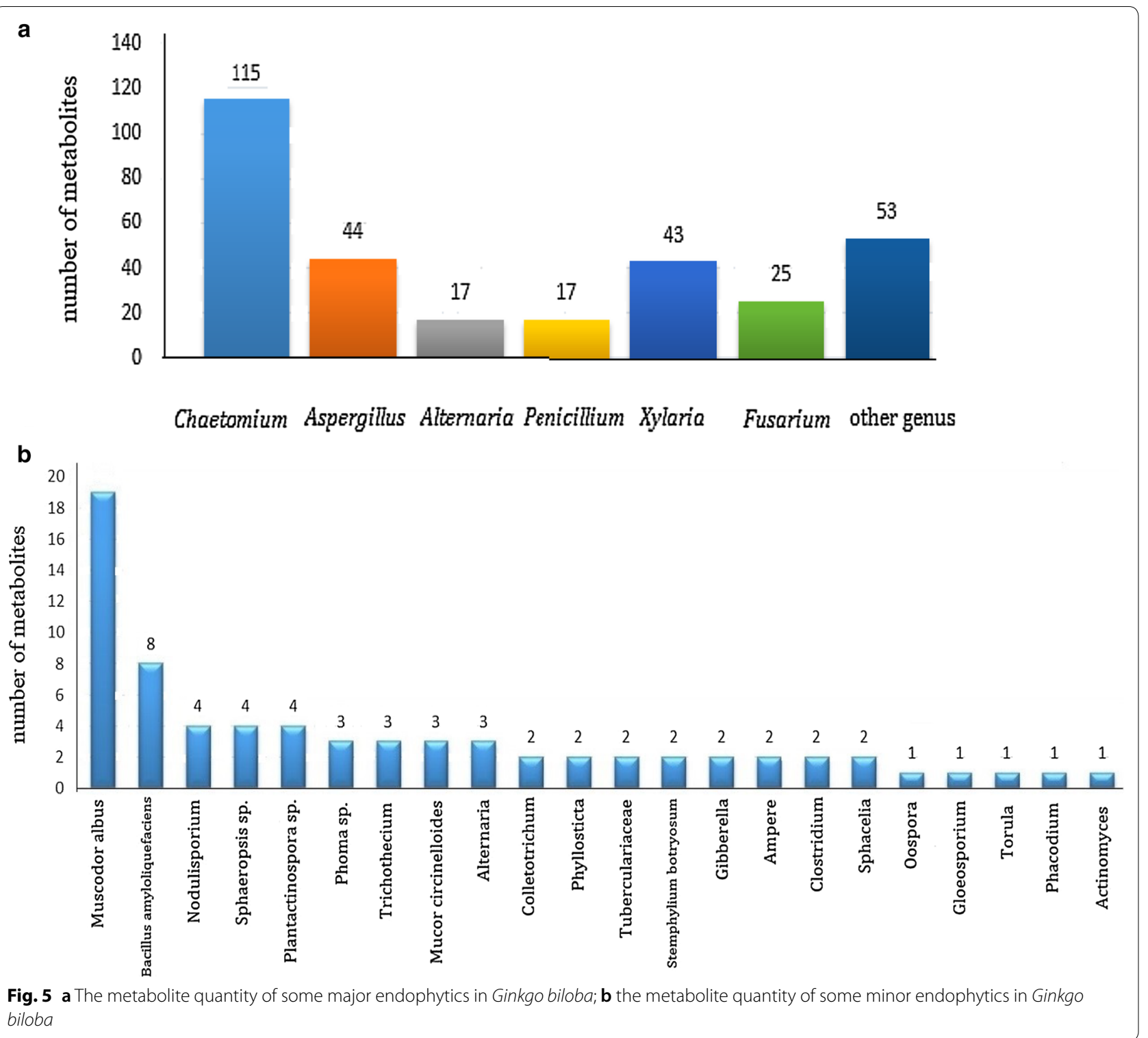

and a secondary alpha-hydroxy ketone. It has a role as a Chaetomium metabolite and an antineoplastic agent.

One new cytochalasan alkaloid, chaetoglobosin V(b), together with two structurally related known compounds, chaetoglobosin $\mathrm{V}$ and chaetoglobosin $\mathrm{G}$, were isolated from the ethyl acetate extract of a culture of the endophytic fungus Chaetomium globosum, associated with the leaves of G. biloba tree. The structures of the isolated compounds were elucidated by spectroscopic methods including 1D and 2D NMR and mass spectrometry. The absolute conStruration of chaetoglobo$\sin \mathrm{V}(\mathrm{b})$ was established by means of electronic circular dichroism (CD) spectroscopy. The correlation between compounds was demonstrated by a biomimetic transformation of chaetoglobosin $G$ under mild conditions in chaetoglobosins $\mathrm{V}$ and $\mathrm{V}(\mathrm{b})$. The isolated metabolites were tested against some phytopathogens [22].

The compound flavipin isolated from Chaetomium globosum CDW 7 has strong antioxidant activity [23]. Chaetomium globosum ZY-22 could produce two polyhydroxylated steroids [24] and two other important compounds bilobalide, ginkgolides are to be beneficial to human health [26]. Bilobalide has neuroprotective effects [27] as well as inducing the liver enzymes CYP3A1 and 1A2 which may be partially responsible for interactions between gingko and other herbal medicines or pharmaceutical drugs; while ginkgolide has been investigated for its potential to reducing migraine frequency [28]. Ergosterol peroxide ( $5 \alpha, 8 \alpha$-epidioxy-22E-ergosta- 6,22 dien-3 $\beta$-ol) is a steroid derivative. It has been reported to 


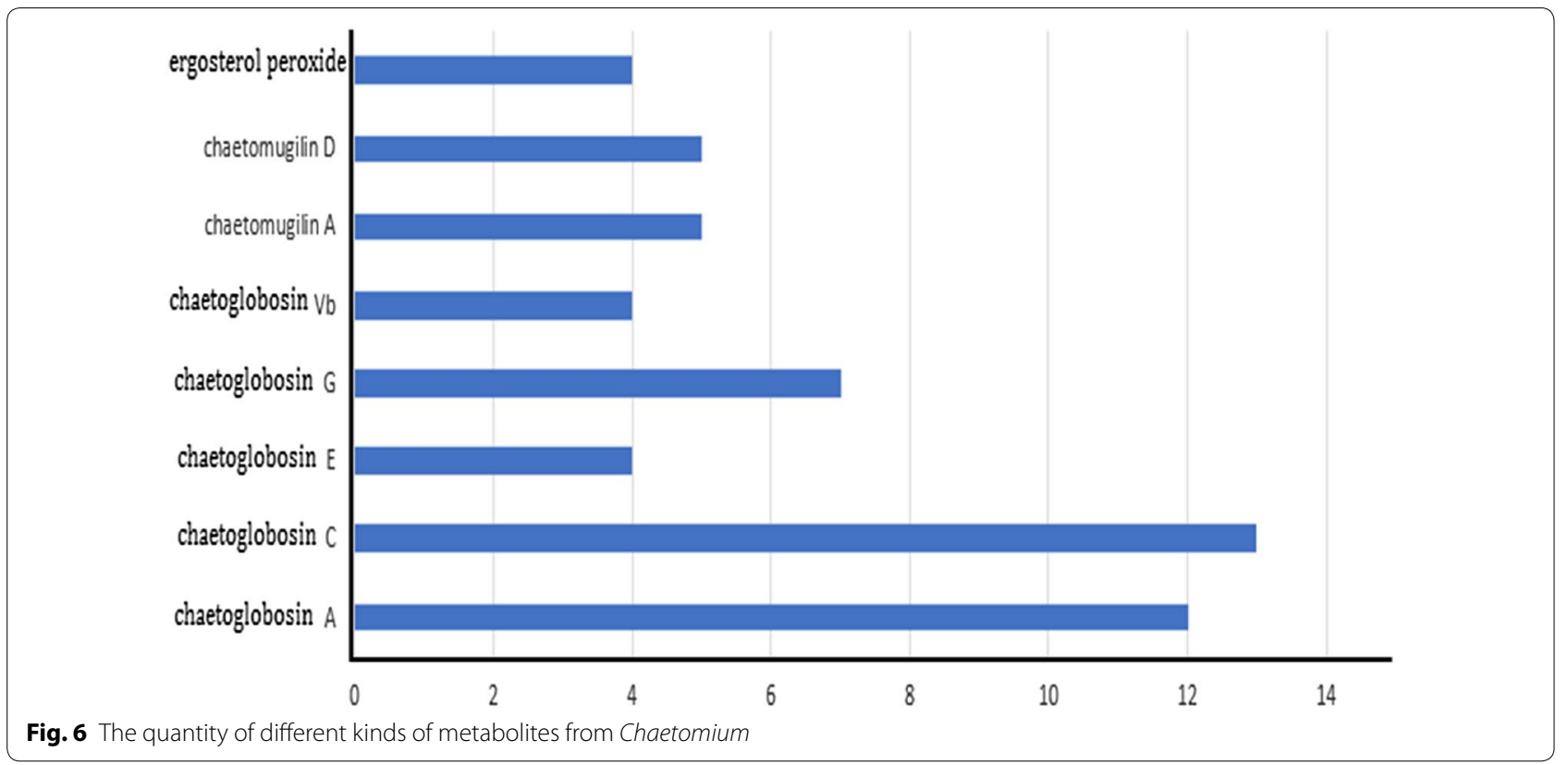

exhibit immune- suppressive, anti-inflammatory, antiviral, trypanocidal and antitumor activities in vitro [27].

\section{Secondary metabolites of Aspergillus}

Aspergillus is the dominant flora of endophytic fungi of G. biloba and was isolated from different parts of $G$. biloba which cultivated in various areas. A total of 44 metabolites were found in the fermentation broth of Aspergillus (see Table 2), among which 3-hydroxy-terphenyl, 4,5-dimethoxycandidusin A, prenylcandidusin $\mathrm{C}$, and prenylterphenyllin were studied most popularly. For 4"-Deoxycandidusin A, 4"'-deoxytripentin, 4'-deoxy3-hydroxyrisperidone, aspergiloid $\mathrm{A}$, coumarin $\mathrm{A}$, and tribenzine, three articles reported about each compound, respectively. Among these metabolites, 3-hydroxy-terphenyl and 4"-deoxycandidusin A, 4"-deoxytripentin have strong inhibitory activity against neuraminidase [29]; 4'-deoxy-3-hydroxytripentin, 3-hydroxy-terphenyl, 4"-deoxycandidusin has moderate activity against human nasopharyngeal carcinoma cell $\mathrm{KB}$, human gastric cancer cell SGC-7901, human colon cancer cell SW1116 and human lung cancer cell A549 [30].

\section{Secondary metabolites of Alternaria}

Alternaria is a very common fungus. It is an important pathogen for plants, human and animal diseases. It is a biological resource with great application potential as well. According to the existing literatures, 17 metabolites were isolated from the fermentation products of Alternaria (see Table 3). Alterperylenol inhibits human telomerase activity. Alterperylenol can inhibit telomerase activity $\left(\mathrm{IC}_{50}=30 \mu \mathrm{M}\right)$, but altertoxin I (dihydroalterperylenol), a structurally related compound, did not affect activity at $1 \mathrm{mM}$. Moreover, alterperylenol and altertoxin I show phytotoxic and antifungal activity [31].

In these metabolites, botulinum toxin and botulinum toxin II have strong cytotoxic activity. When the concentration is $10 \mu \mathrm{g} / \mathrm{mL}$, the mortality rate of brine shrimp is $68.9 \%$ and $73.6 \%$, respectively [32]. Alternaria No. 28 could produce cytotoxic metabolites which have inhibitory potential against some different protein kinases [7].

\section{Secondary metabolites of Penicillium}

Penicillium is widely distributed in nature and generally has a strong biological activity. According to the existing literatures, 17 secondary metabolites were found from the fermentation products of Penicillium sp. in G. biloba (Table 4), and some metabolites were biologically active. The compound arcacic acid is isolated from the fermentation broth of Penicillium commune, which has antibacterial activity and has inhibition activities on 12 kinds of plant pathogens, especially has strong inhibitory activity against Bacillus licheniformis and Sclerotinia sclerotiorum, and the $\mathrm{IC}_{50}$ values are only $39.28 \mathrm{mg} / \mathrm{L}$ and $60.62 \mathrm{mg} / \mathrm{L}$ [33].

The compounds adenosine, deoxyadenosine and adenine which were isolated from the fermentation product of Penicillium sp. YY-20 have a strong scavenging capacity for DPPH free radical [34]. Wu isolated Penicillium cataractum SYPF 7131 from 58 endophytic fungi obtained from the leaves, stems and roots of G. biloba. 


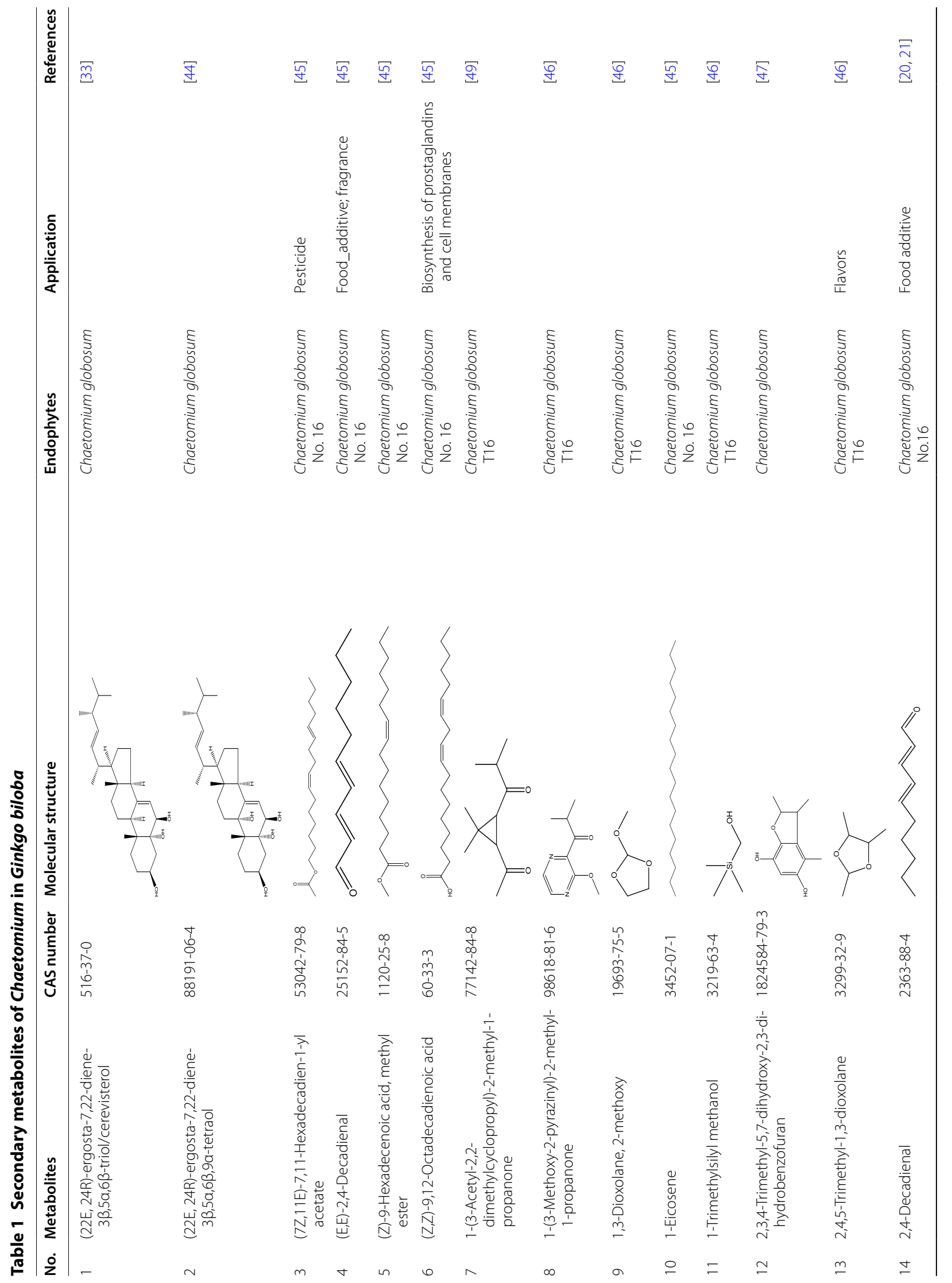




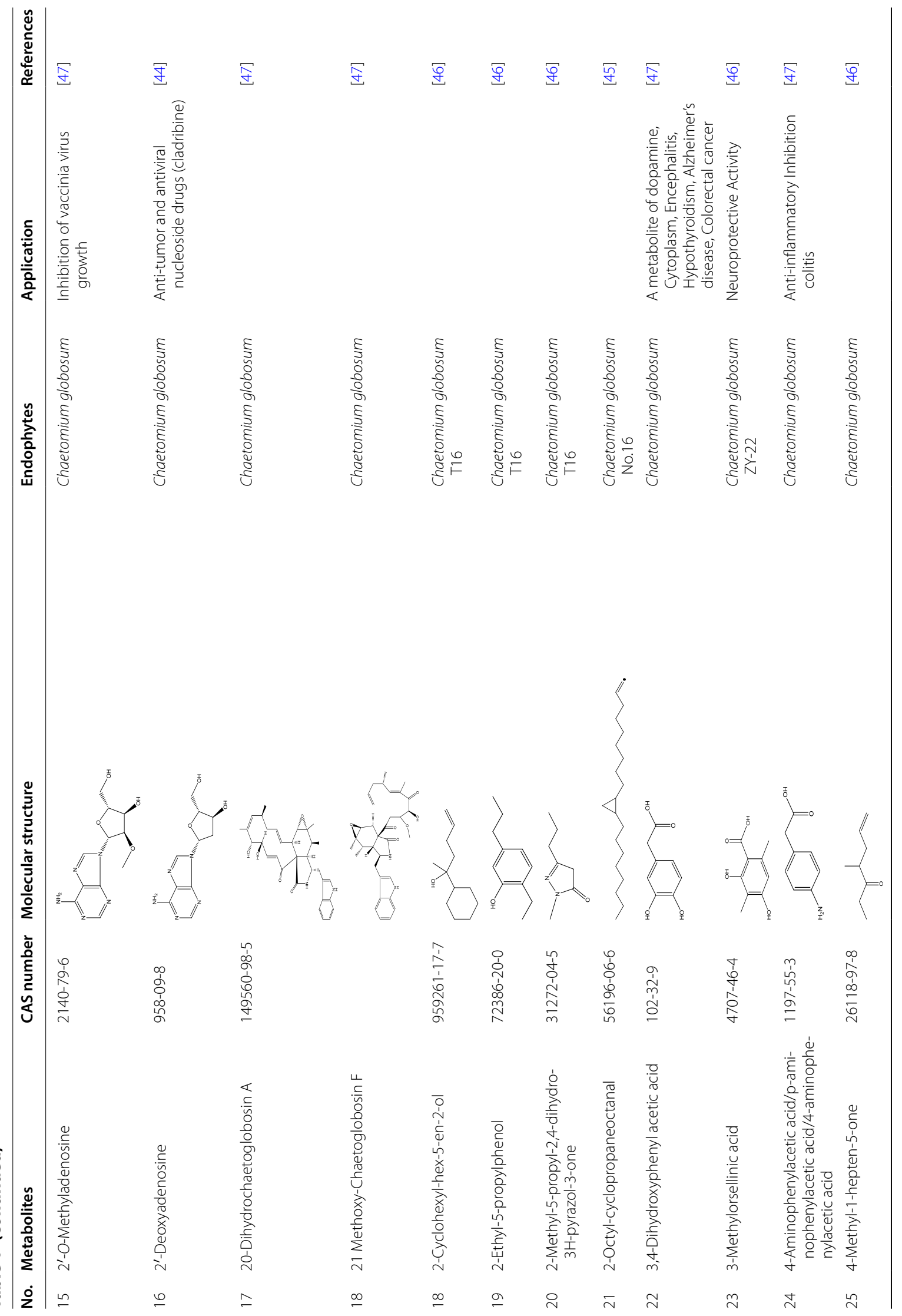




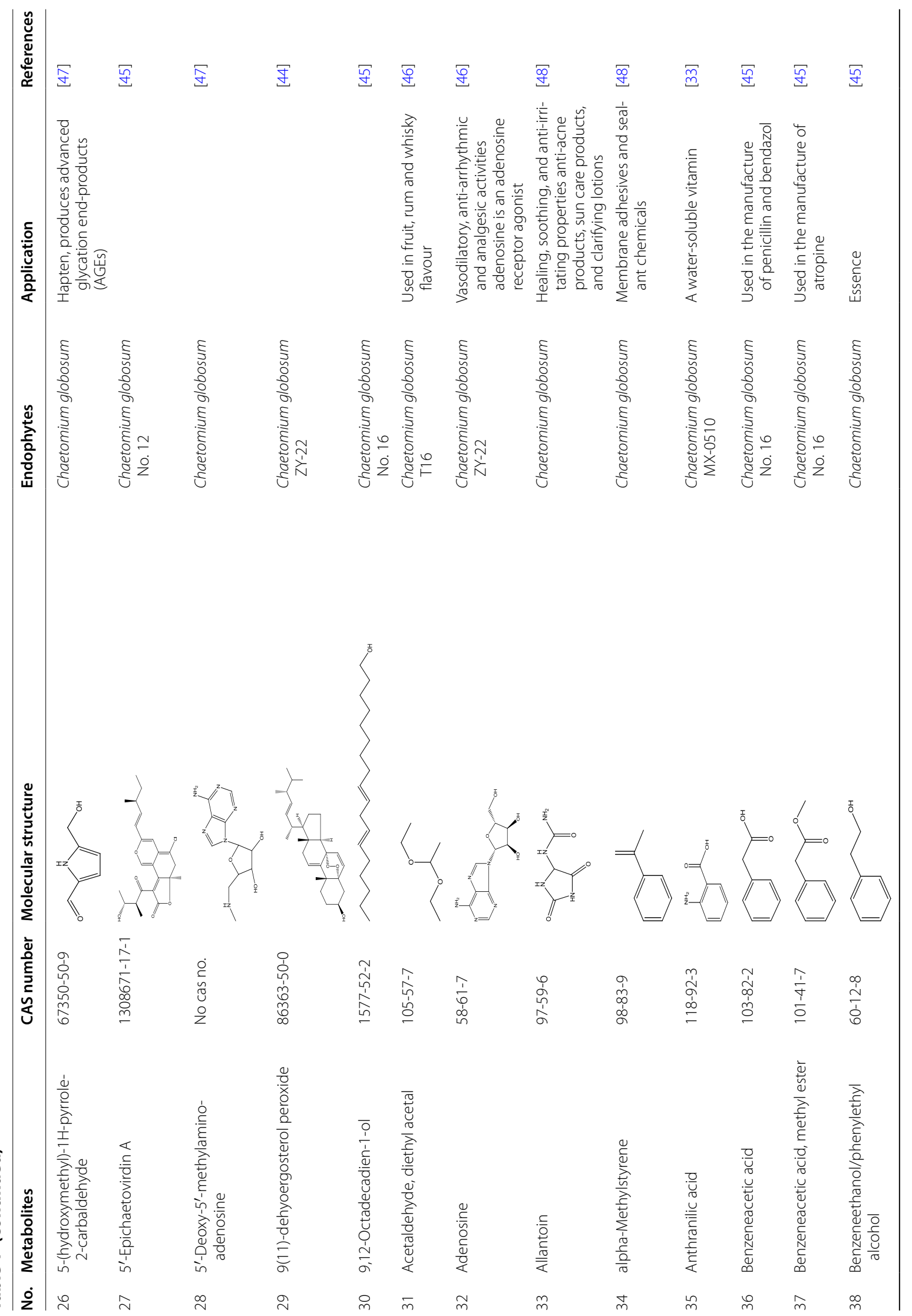


Yuan et al. Chin Med ～(2019) 14:51

Page 12 of 40

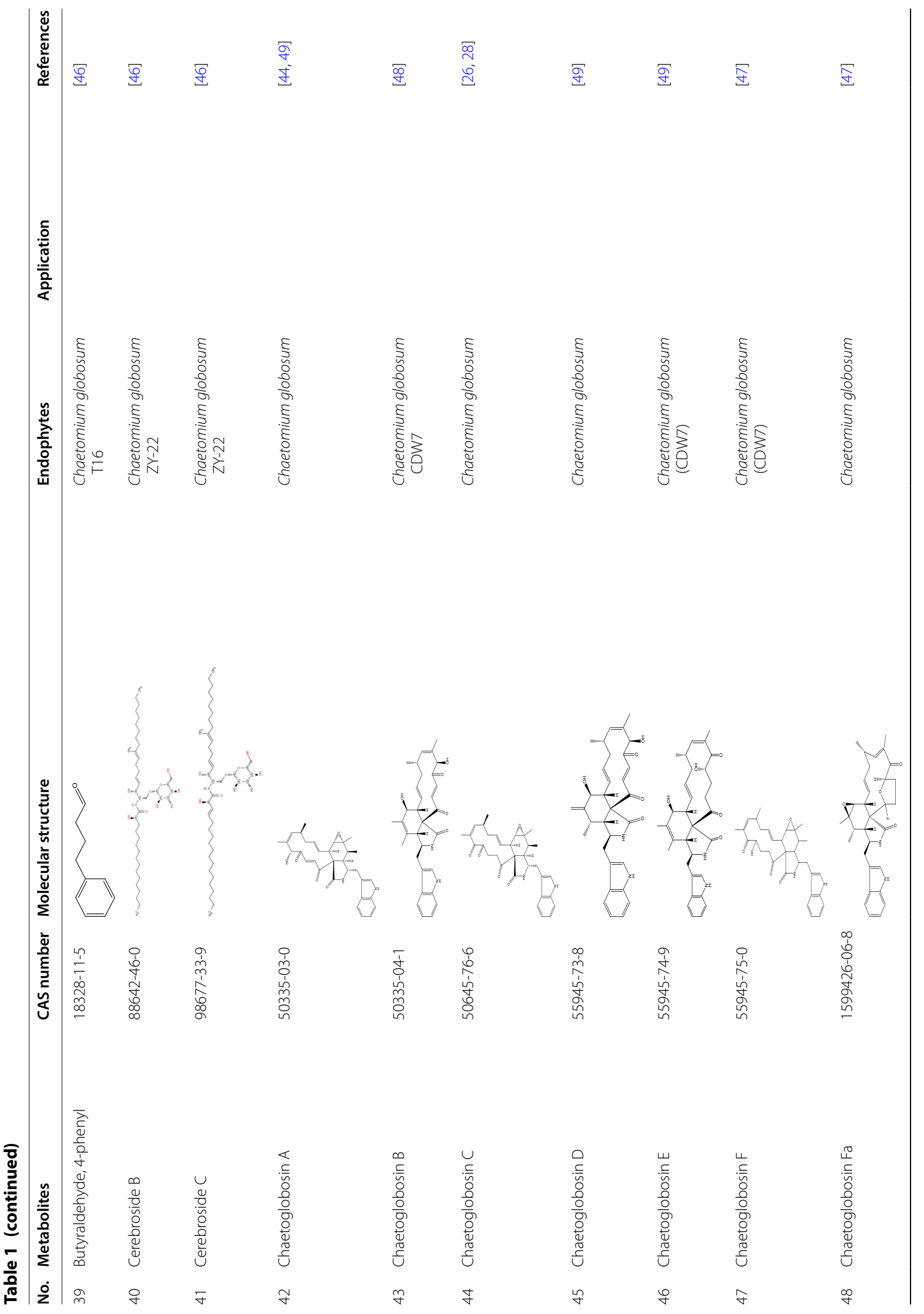




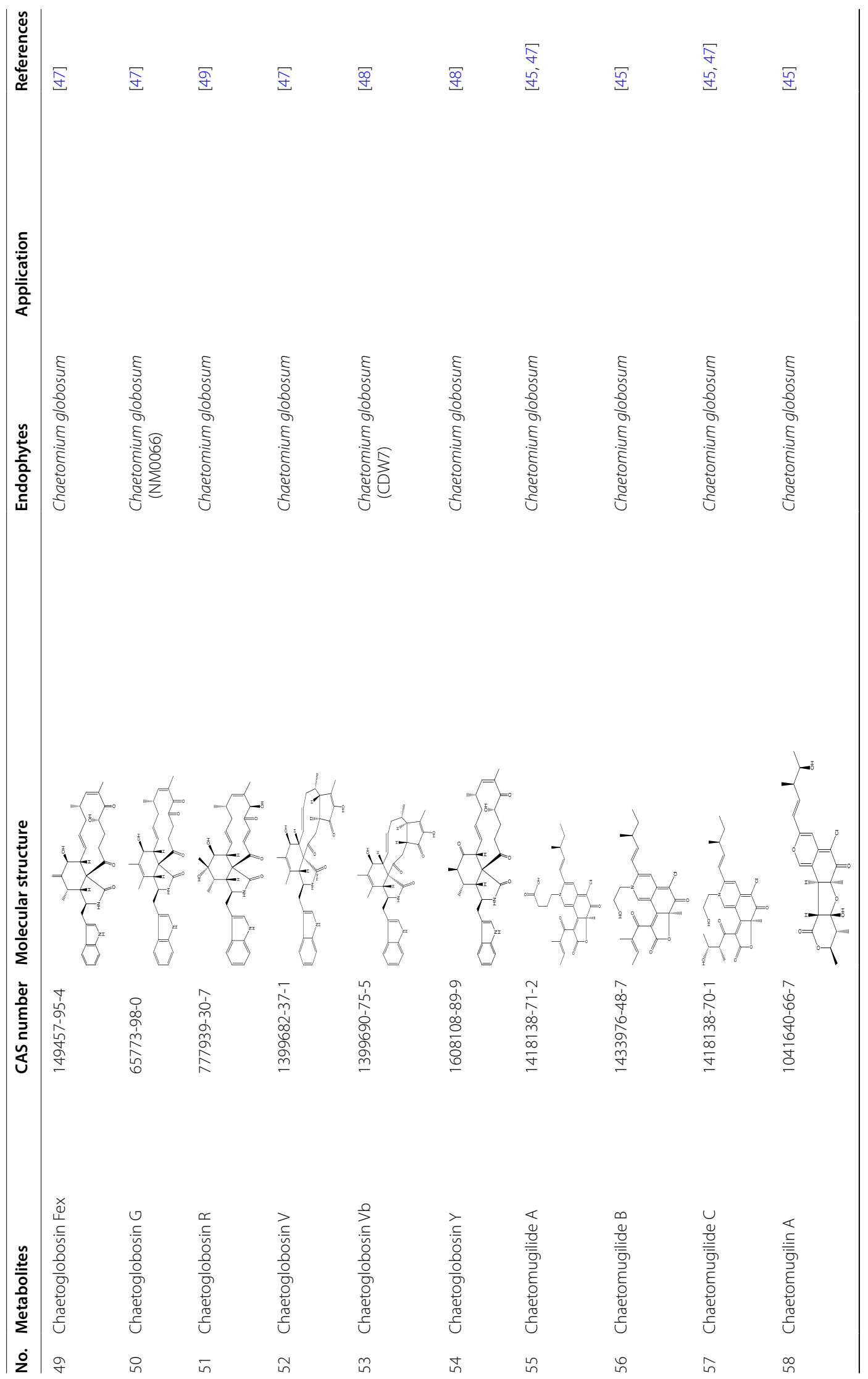




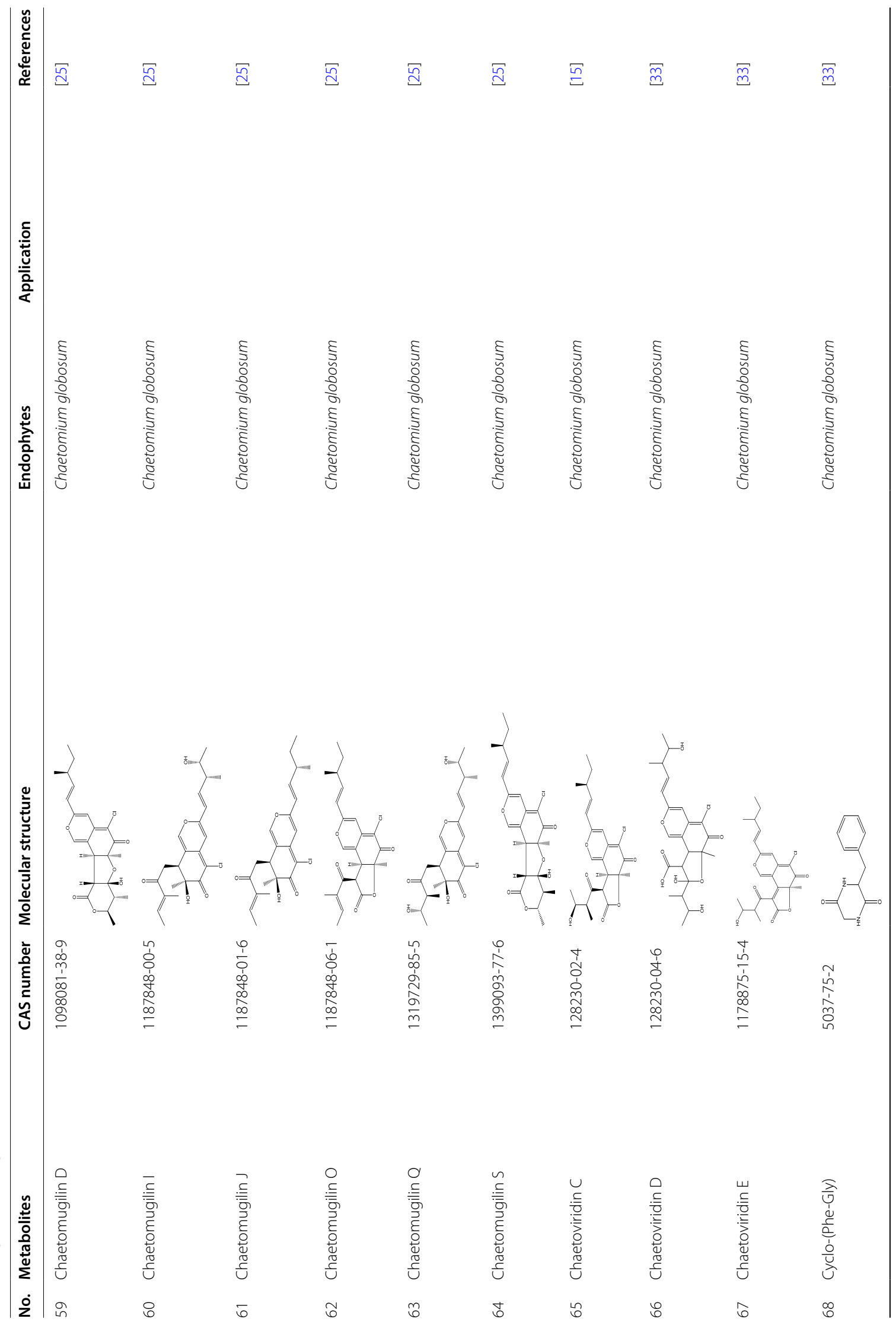




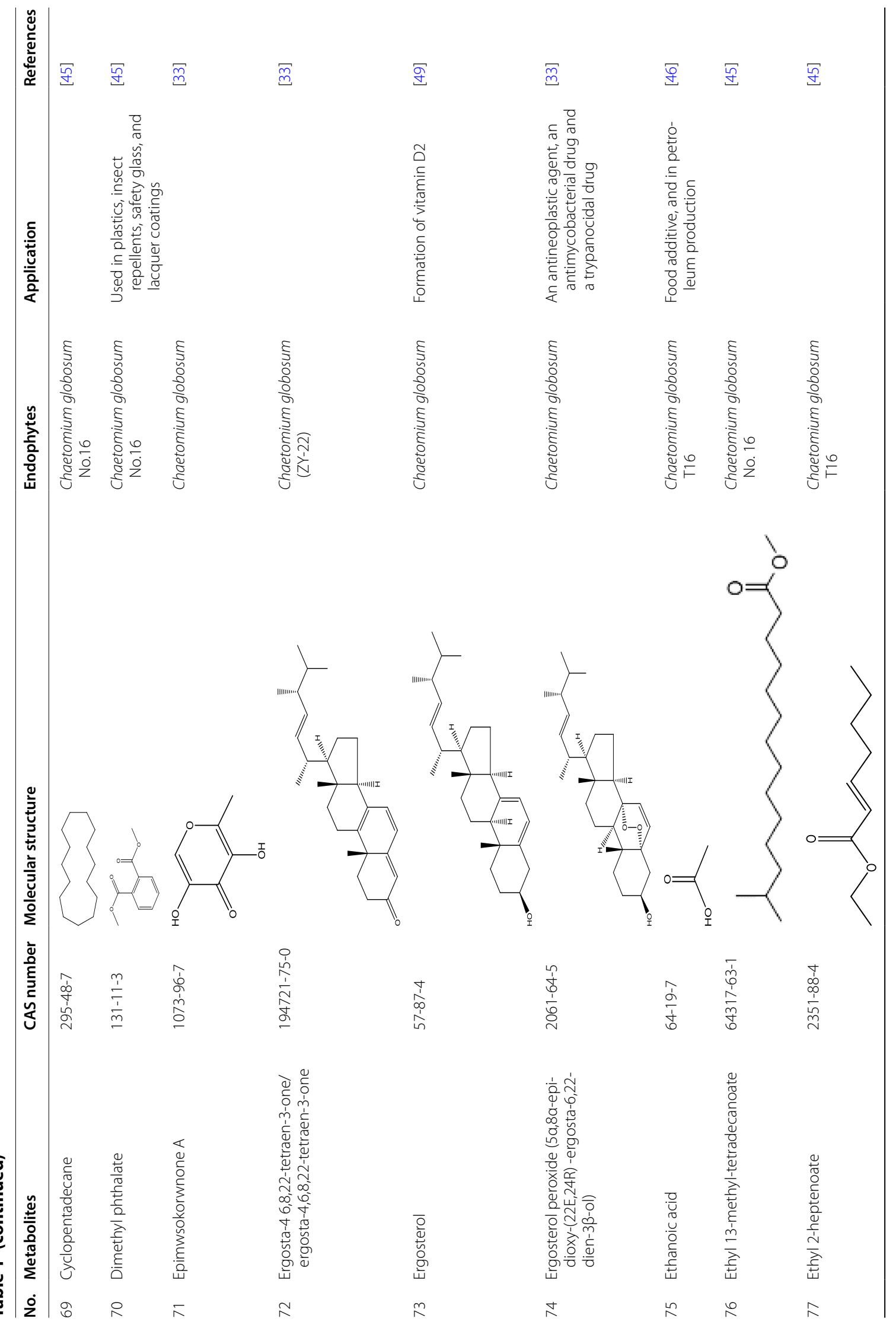



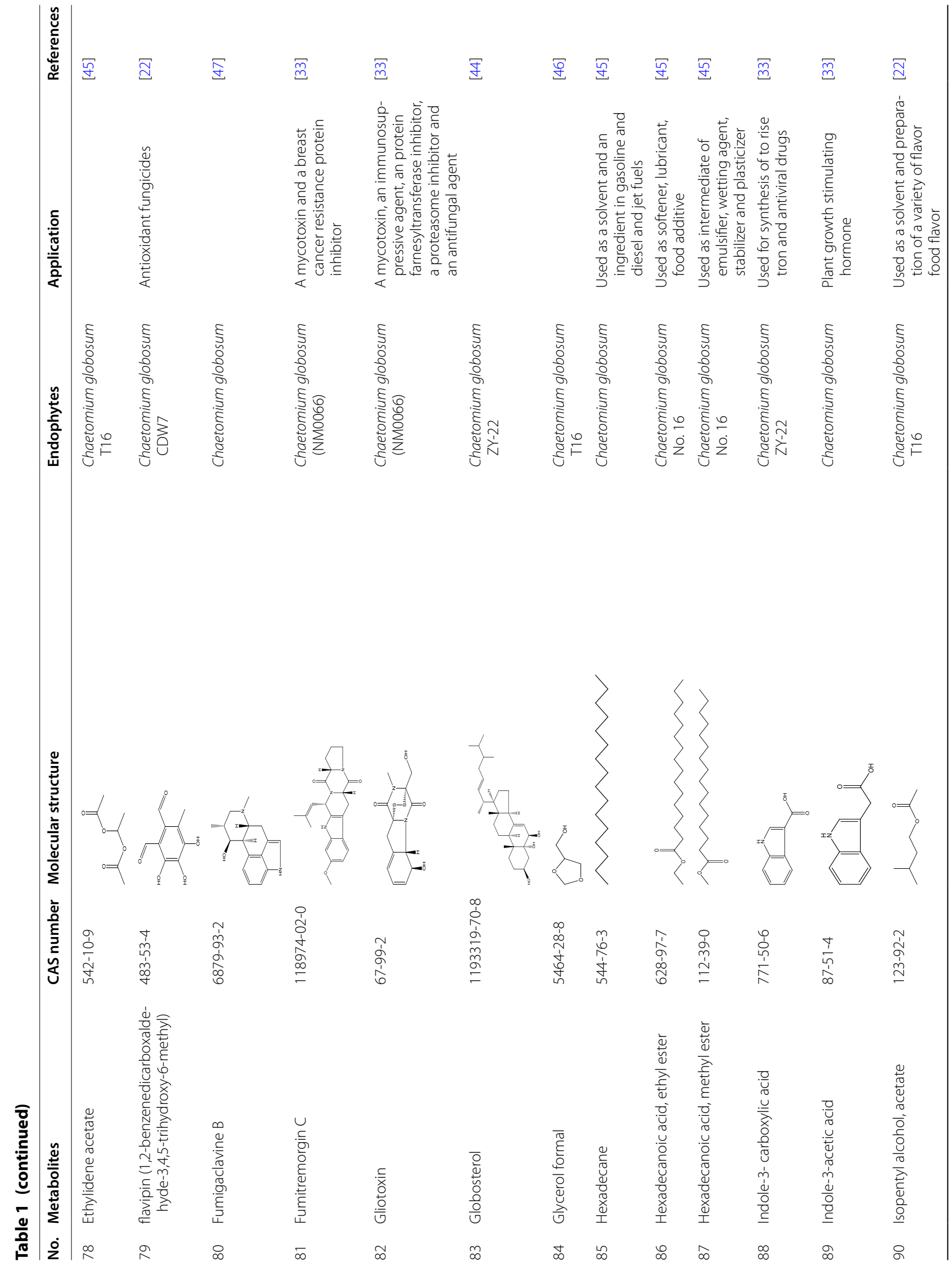


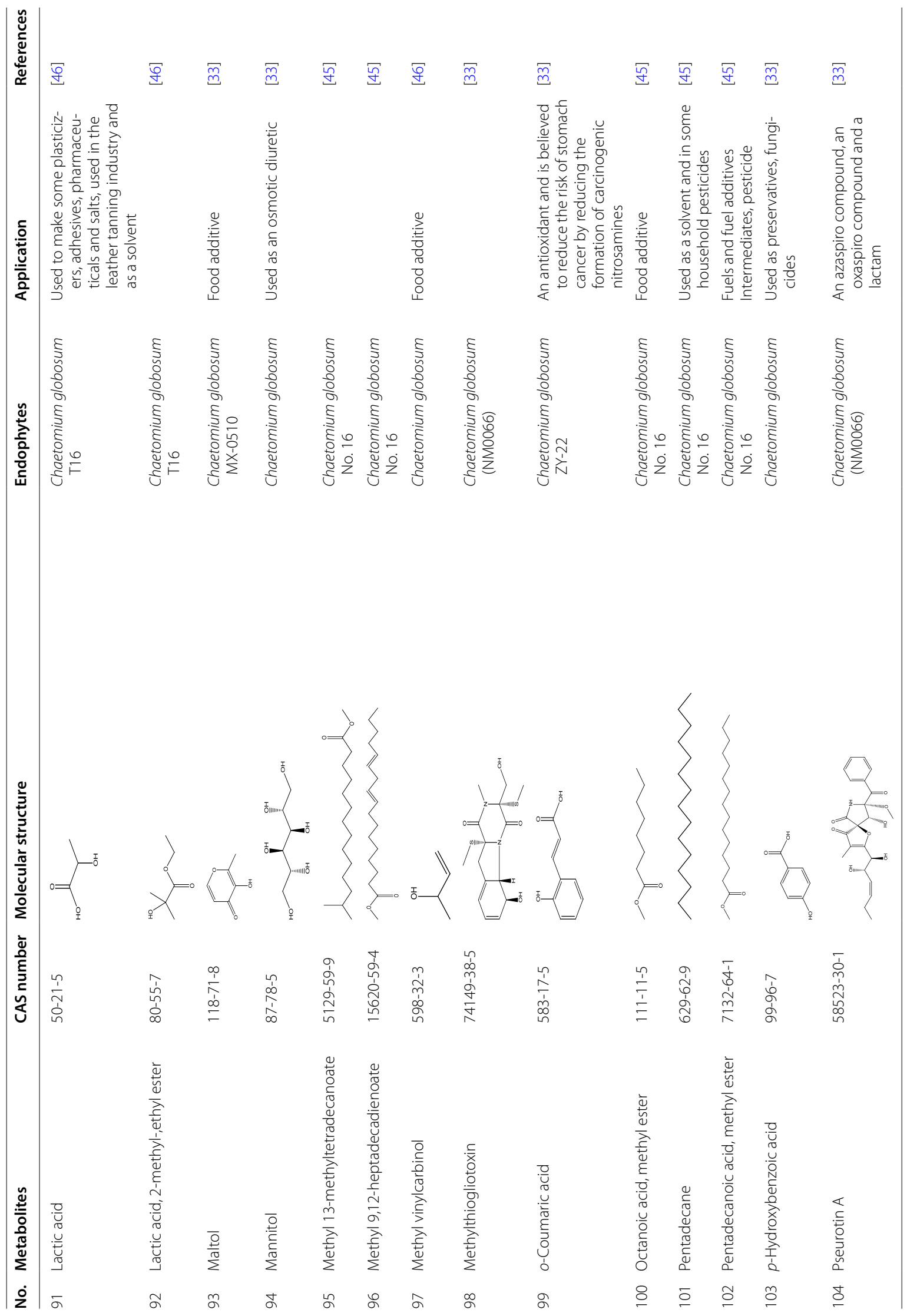




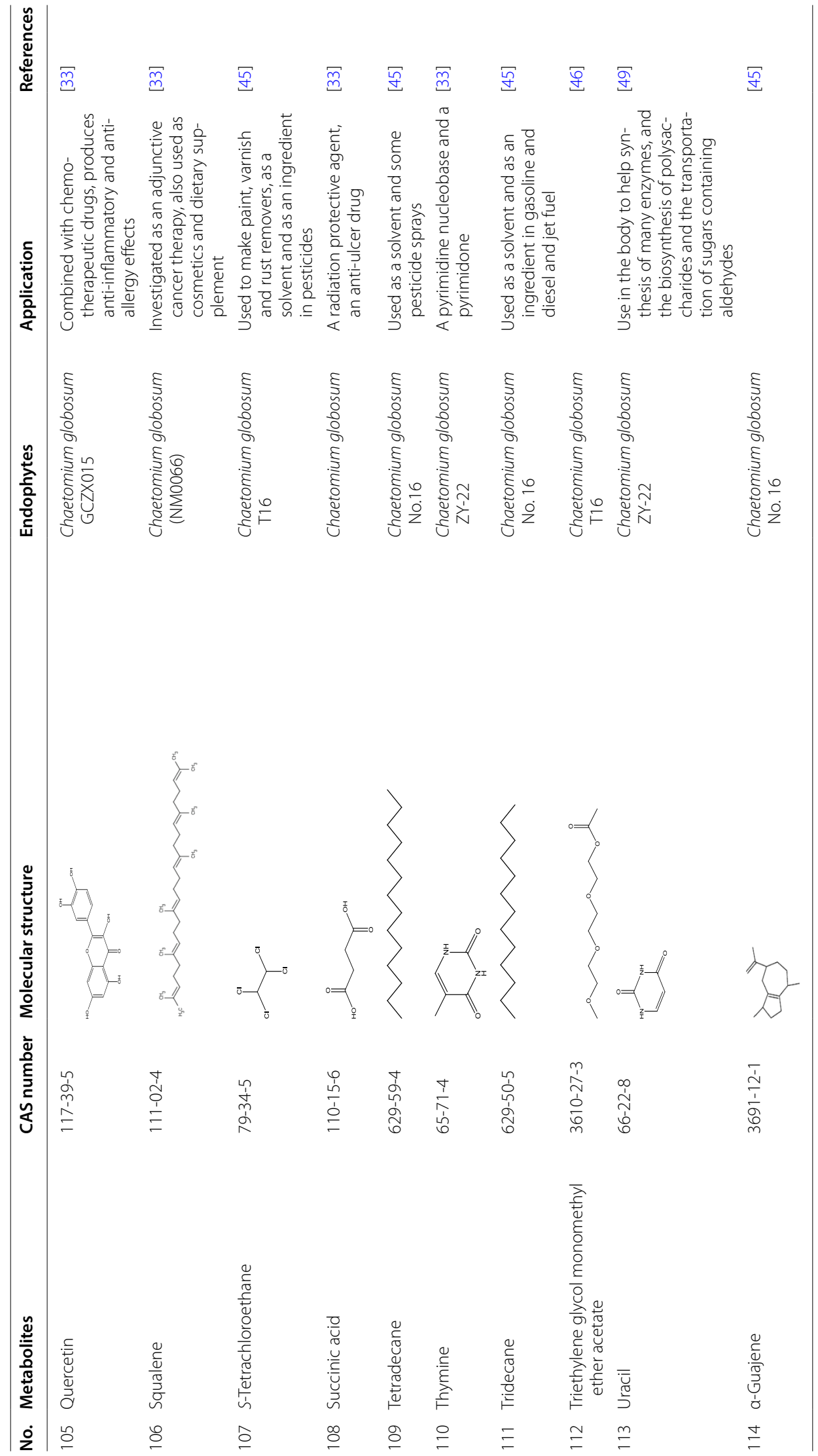



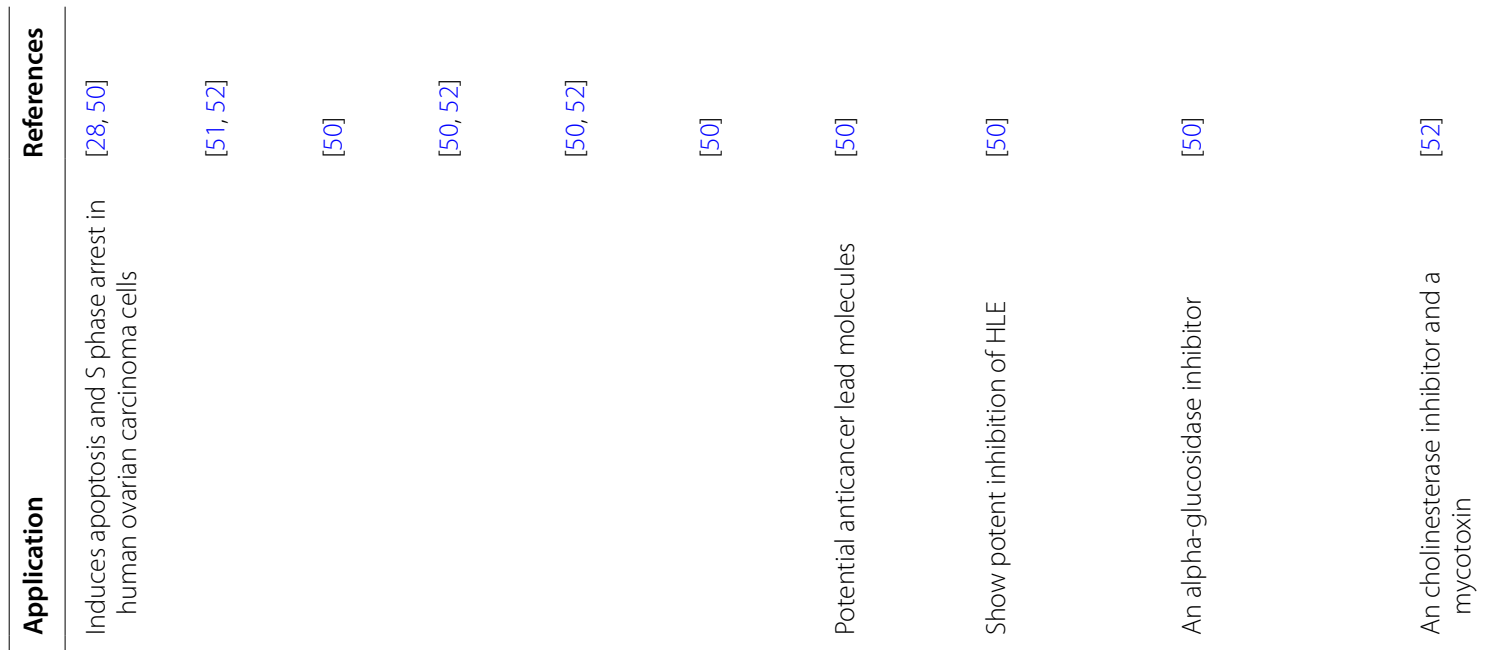

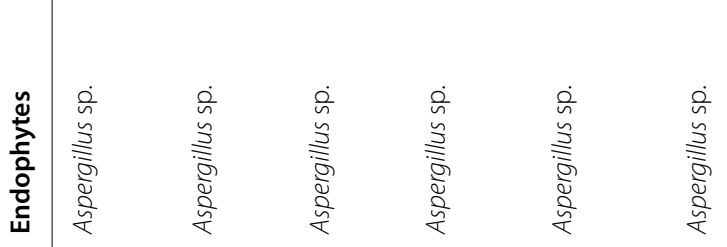
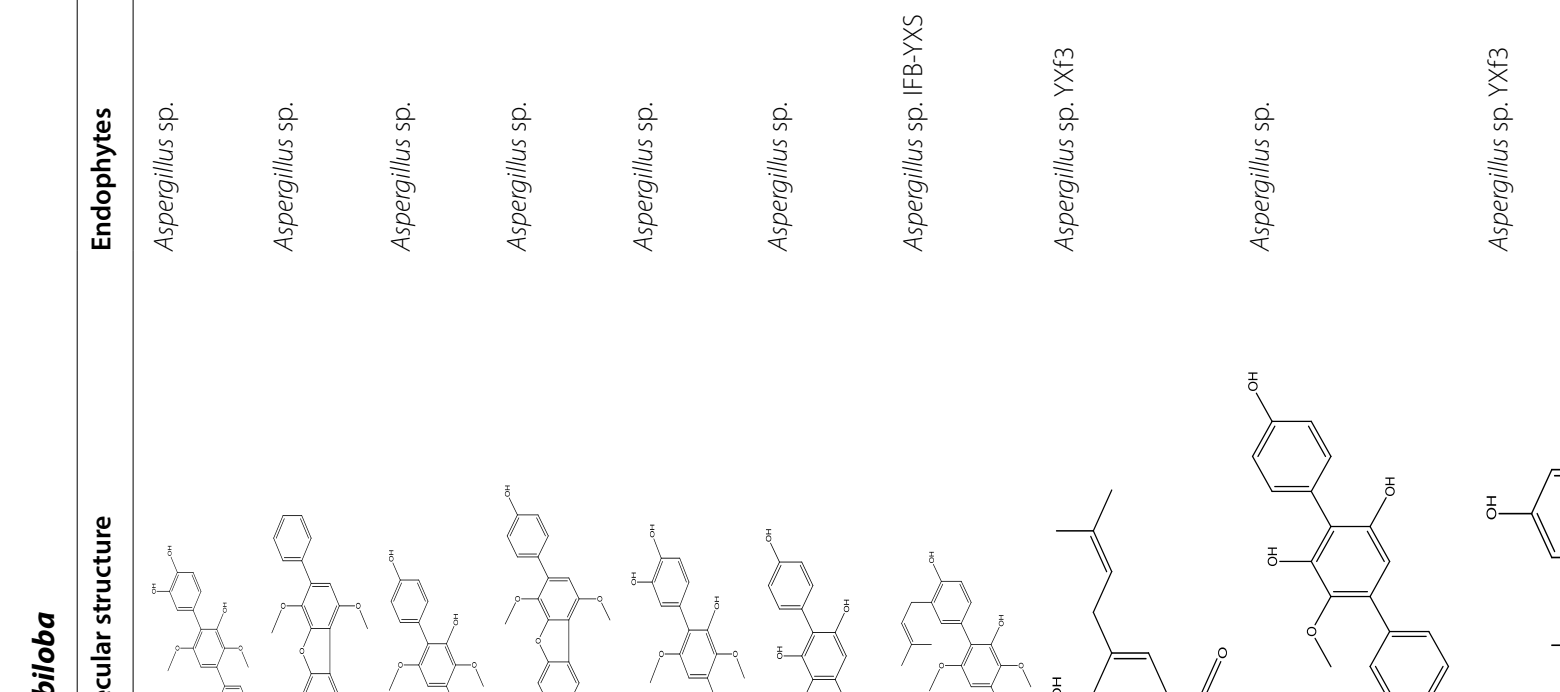

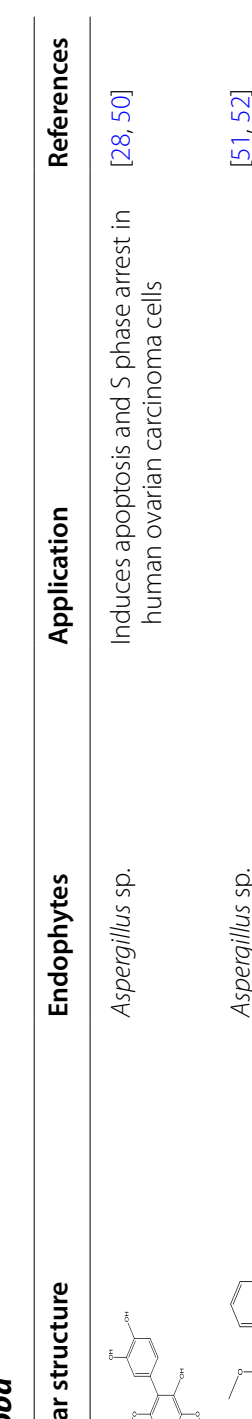<smiles>CCOC(C)C1C2CC3CC(C2)CC1C3</smiles><smiles>[Li]</smiles>
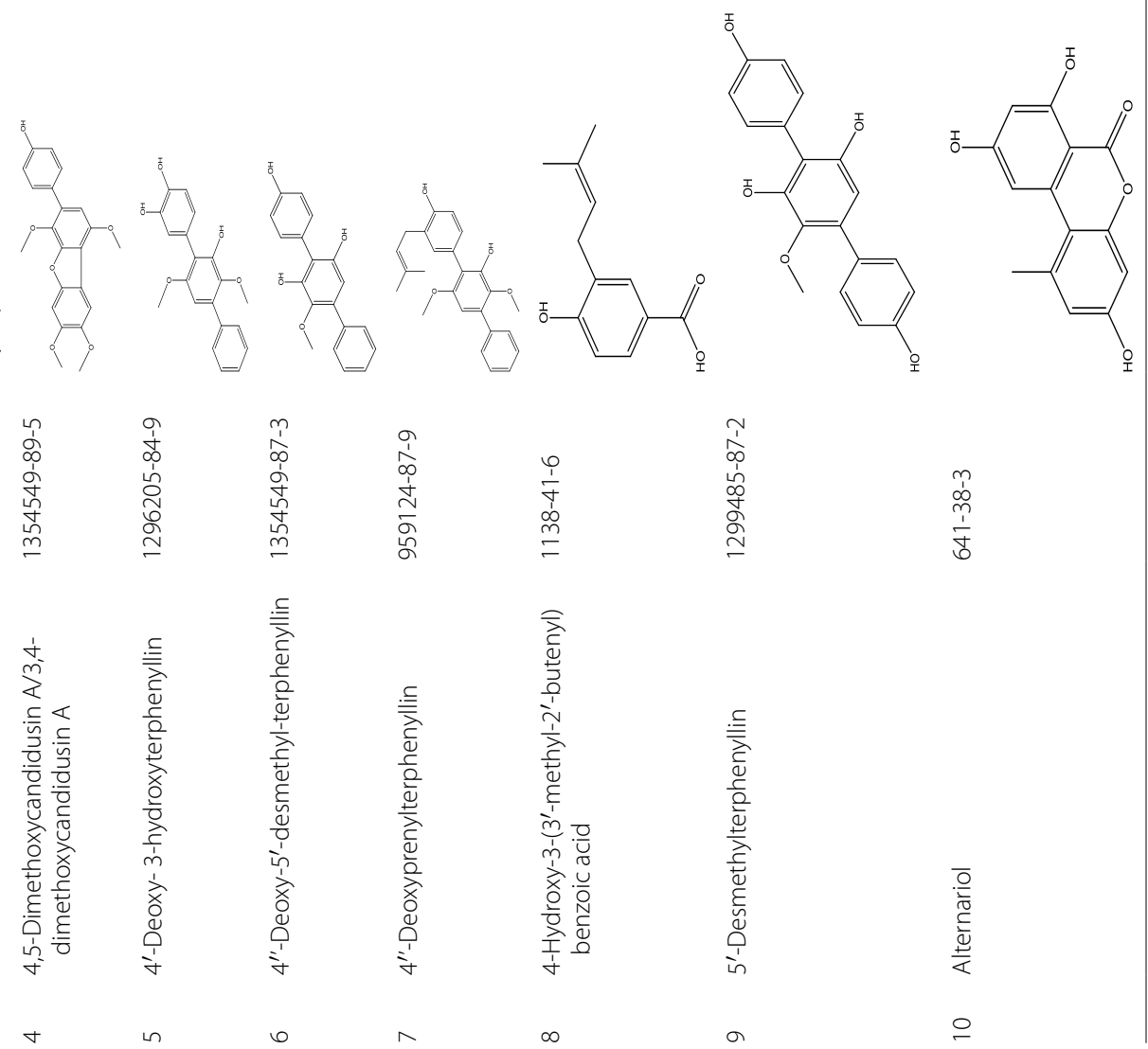

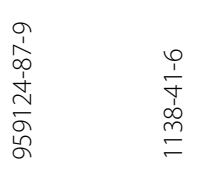
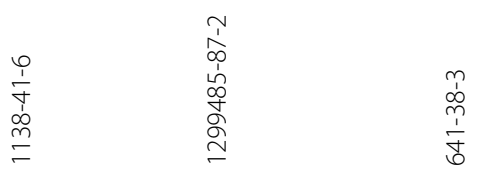


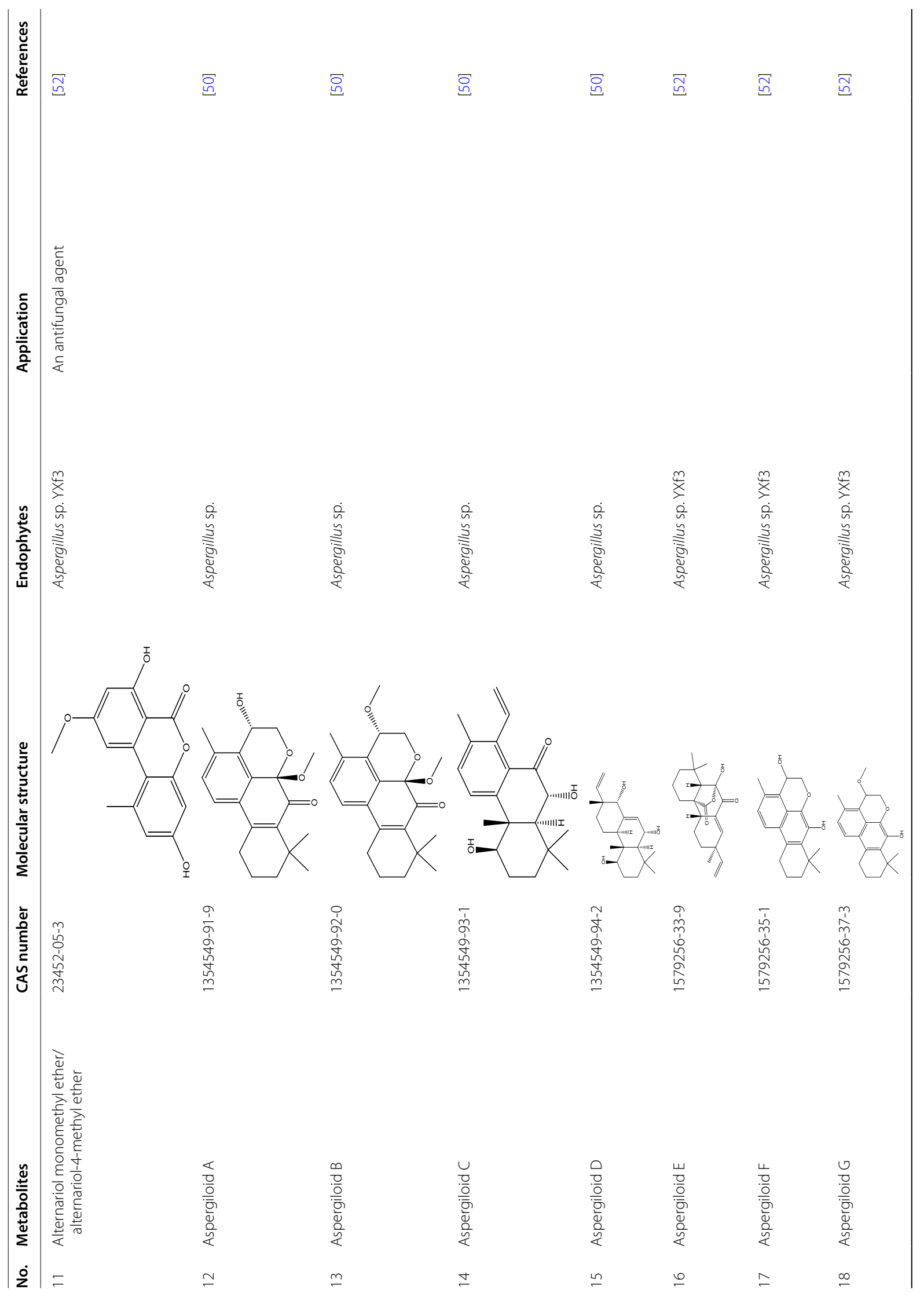




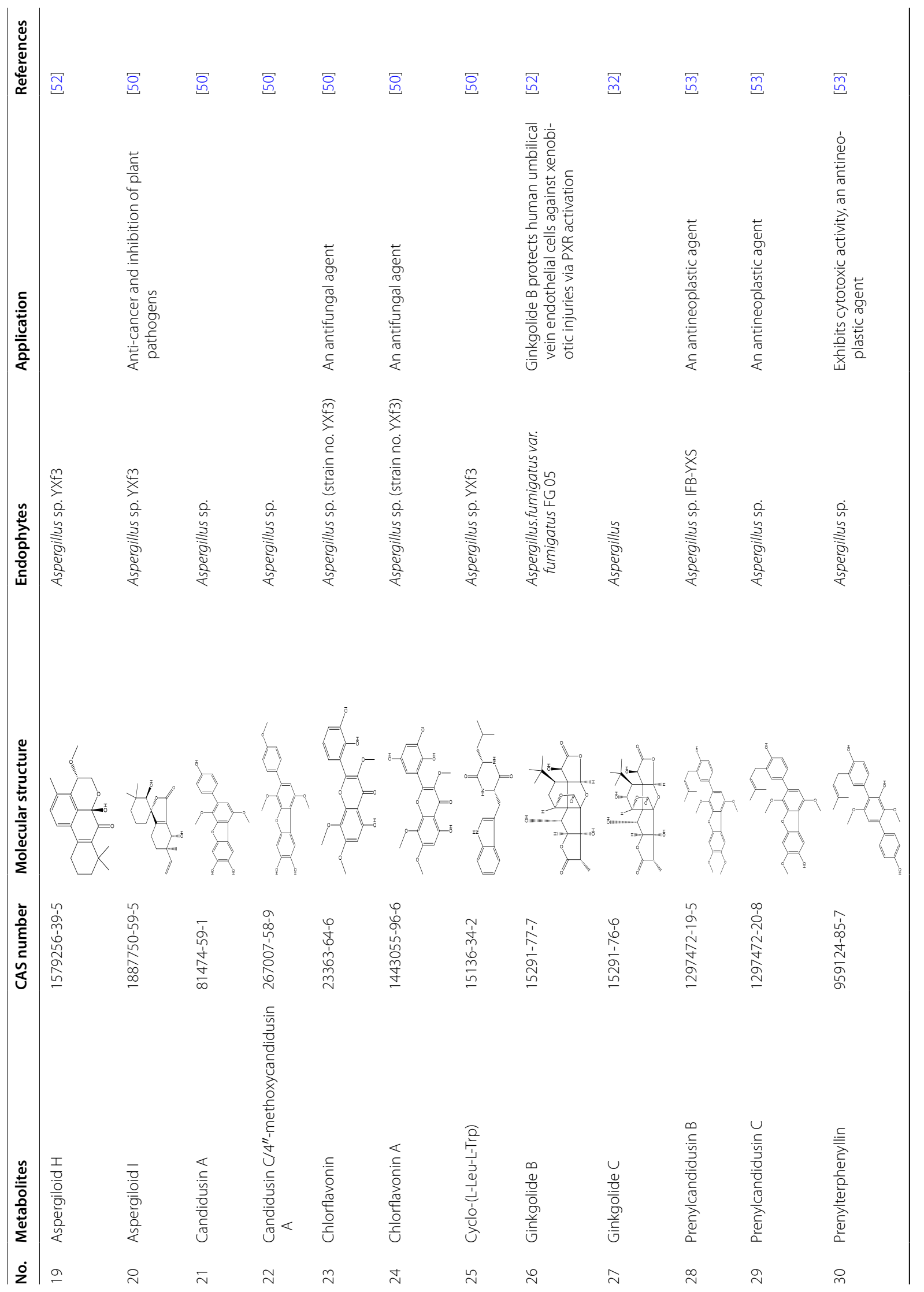




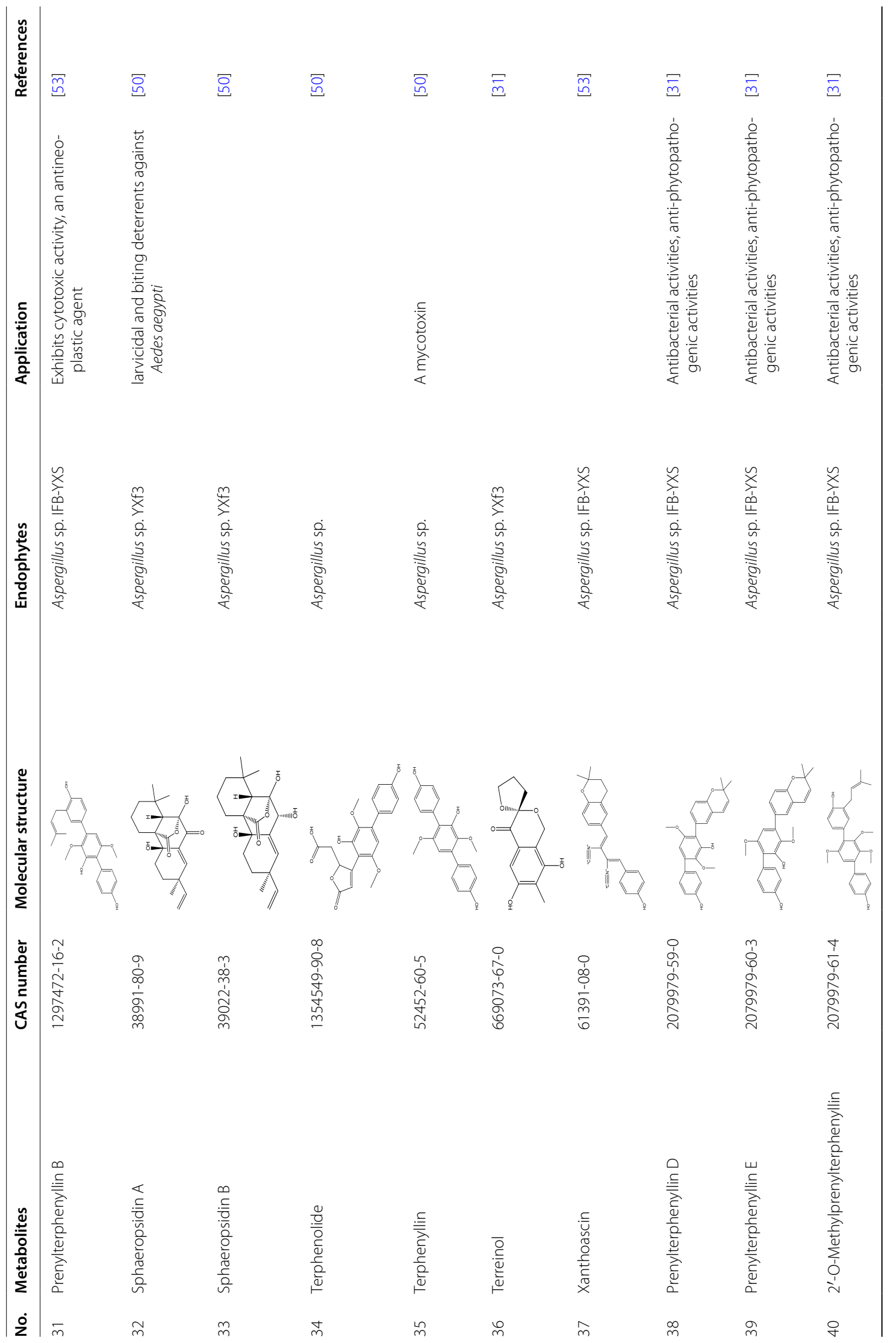




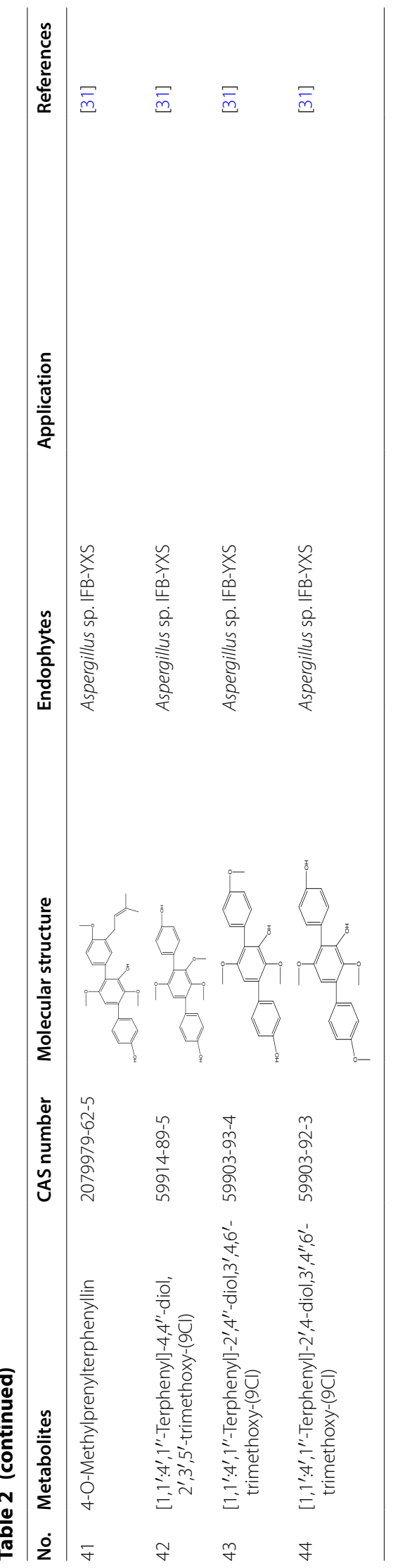



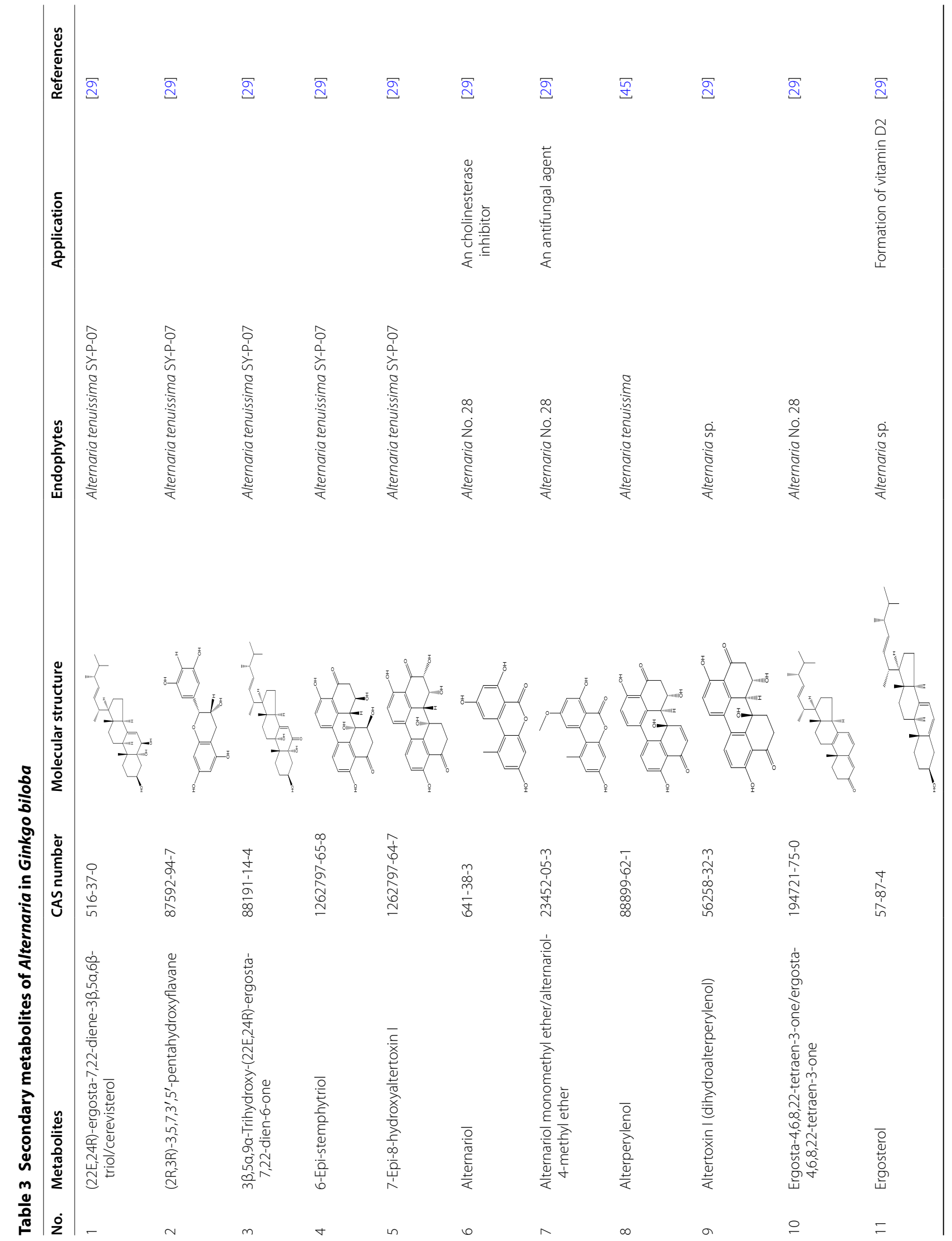


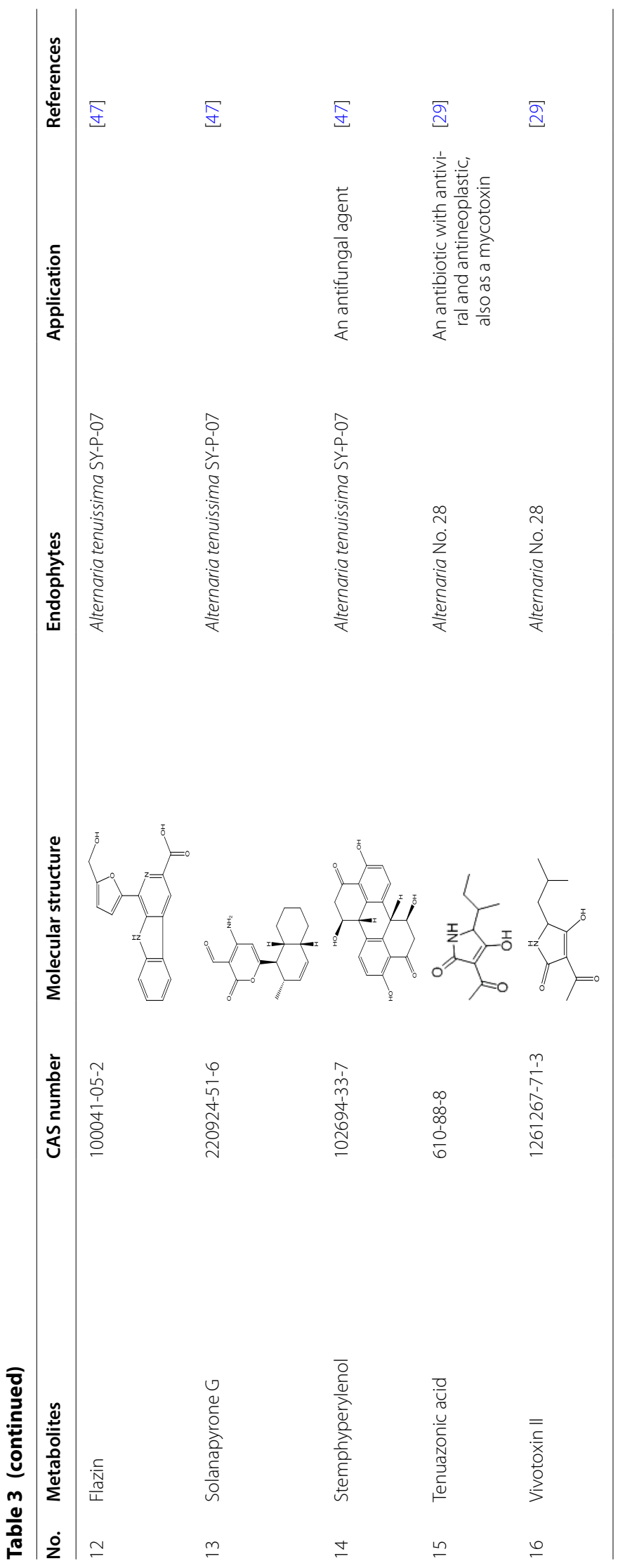




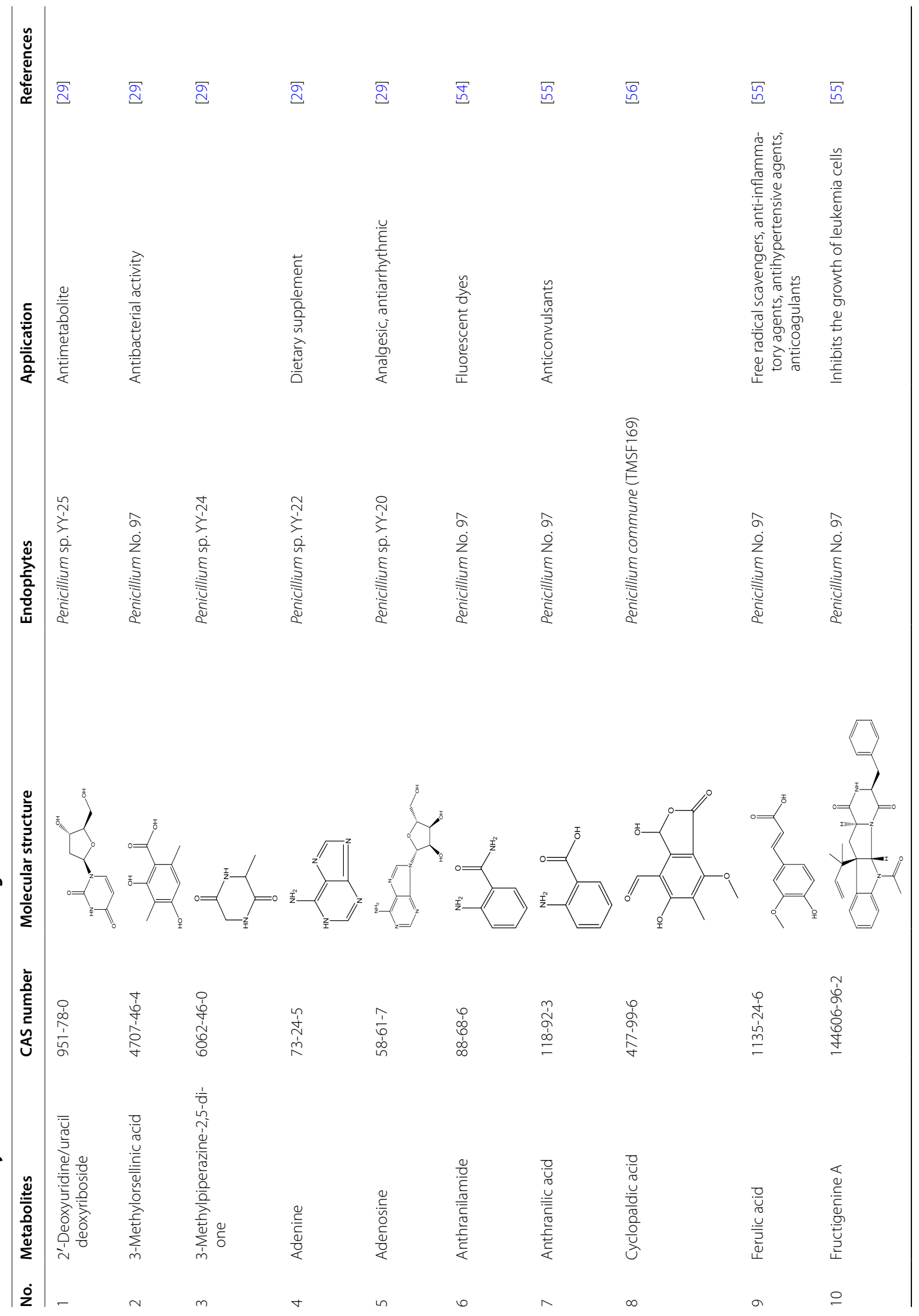




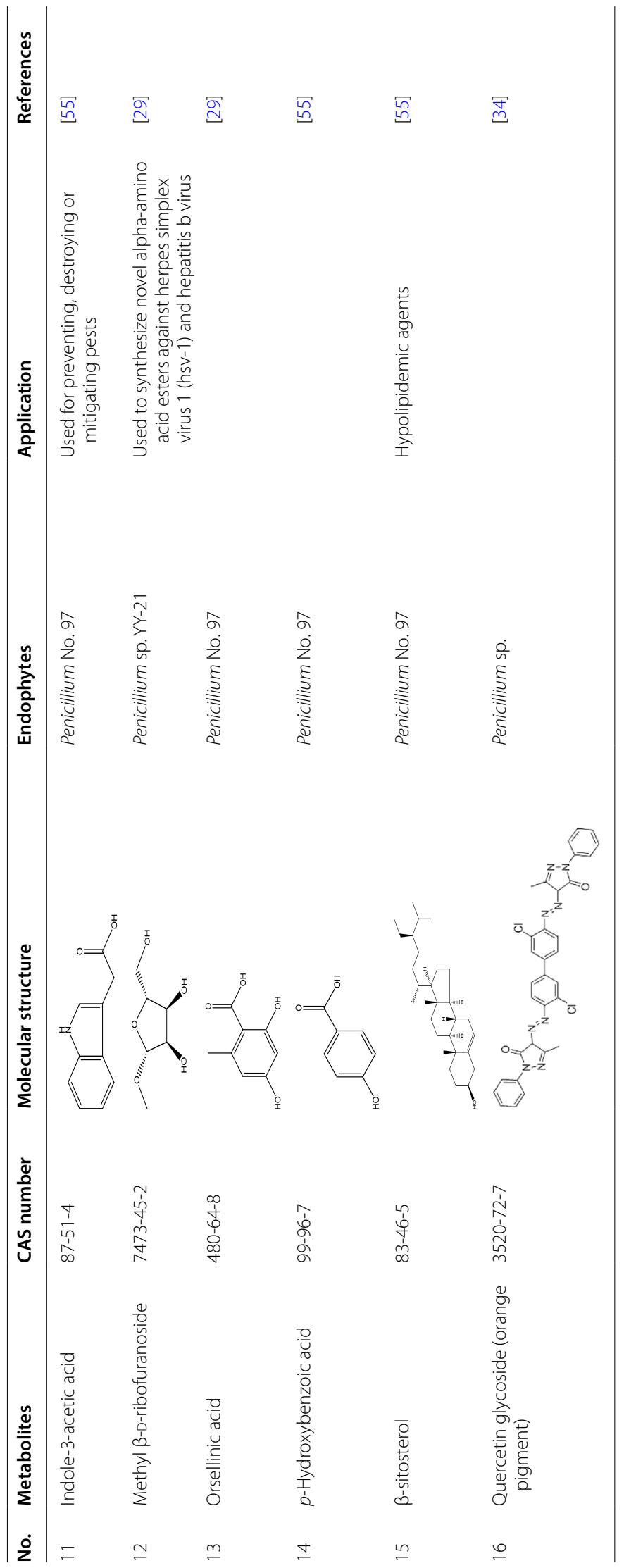




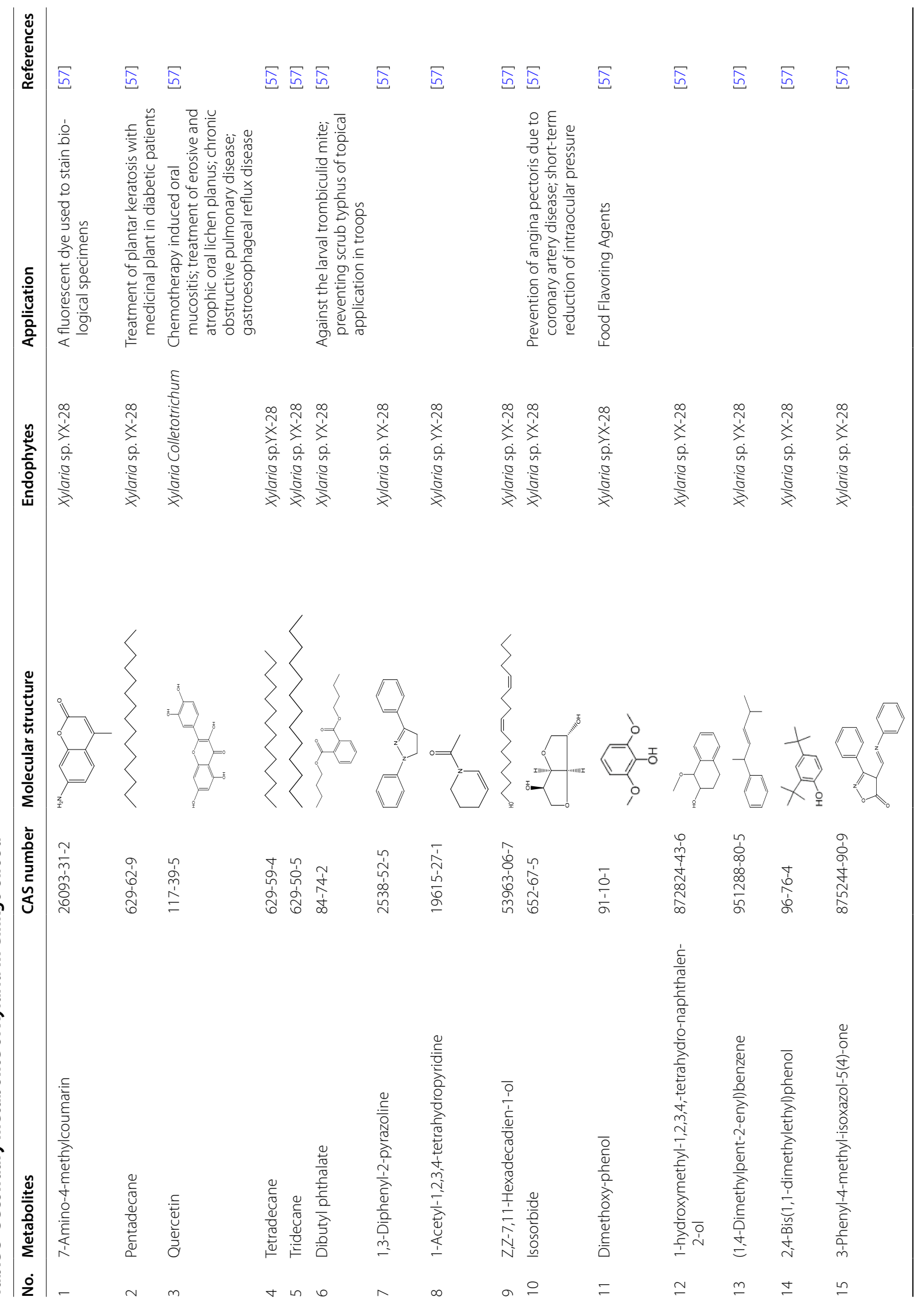



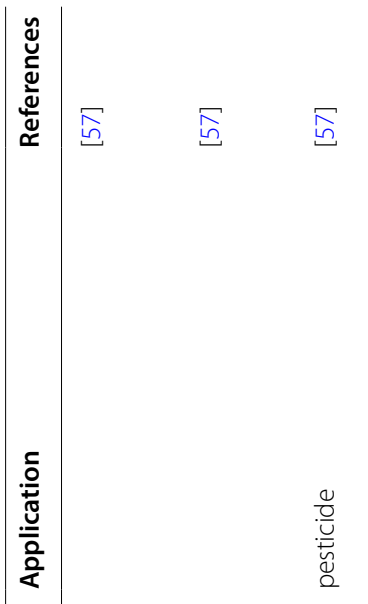

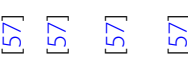

5

E
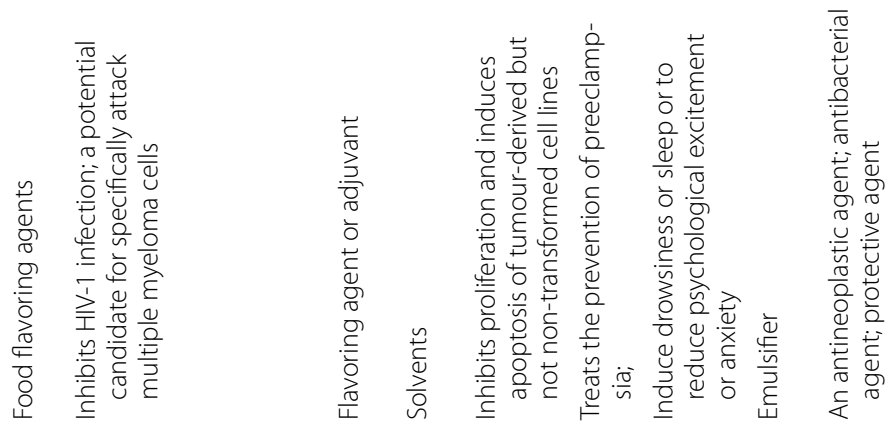

E

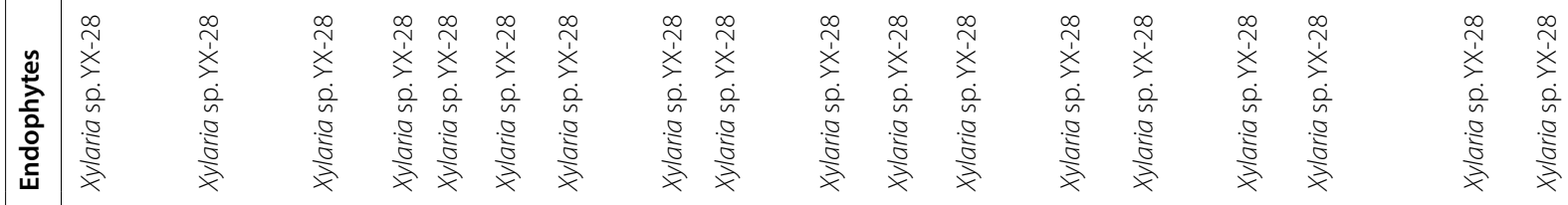
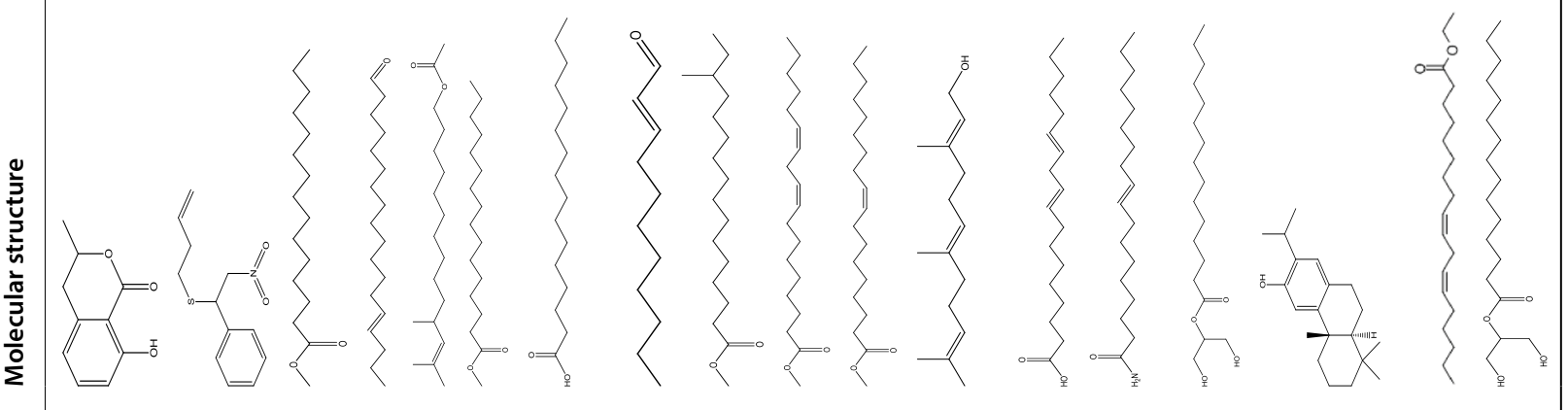

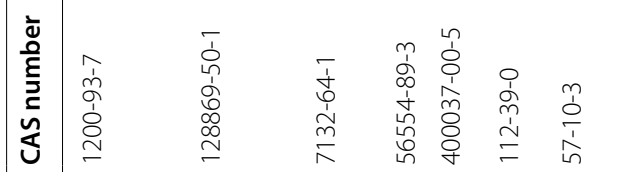

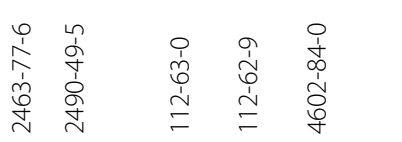

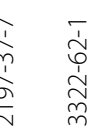

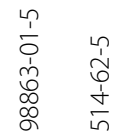

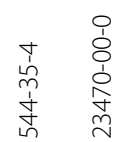
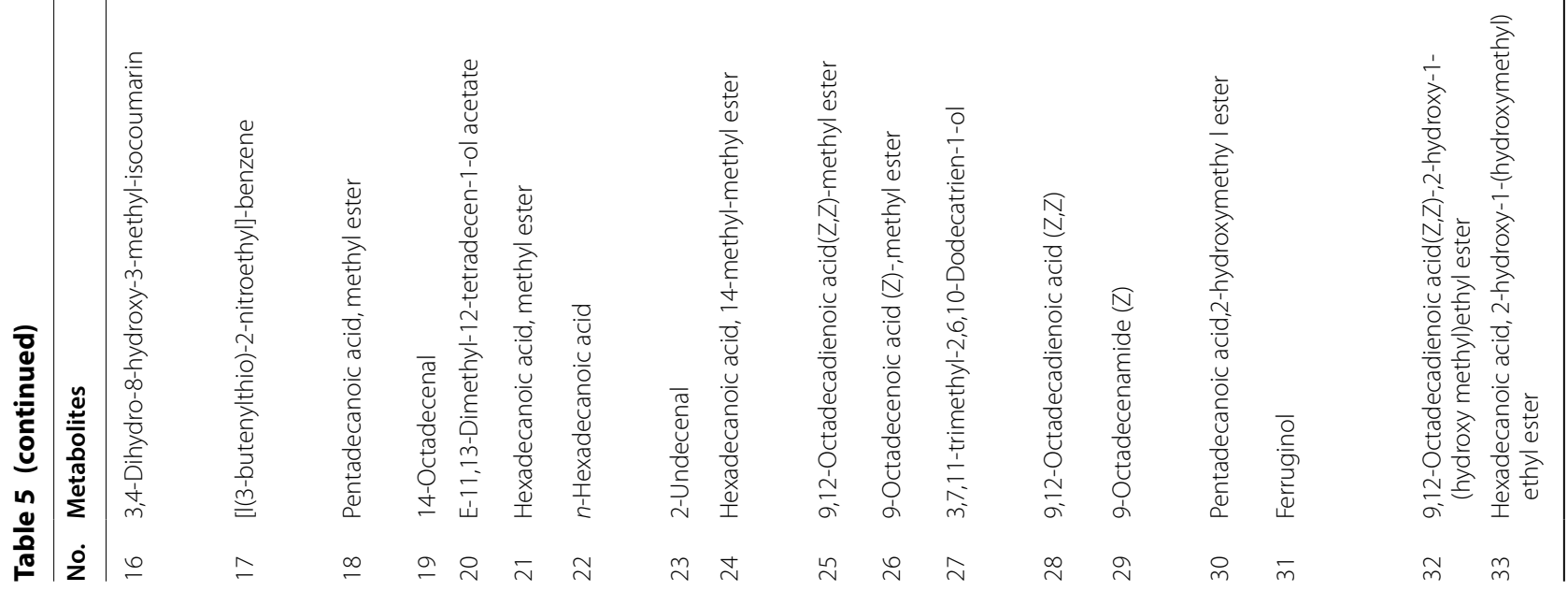


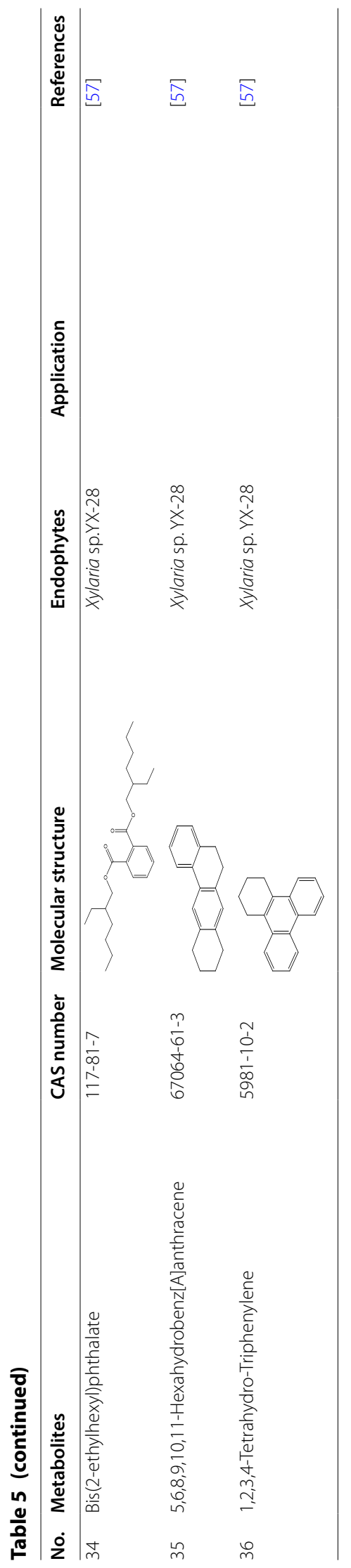




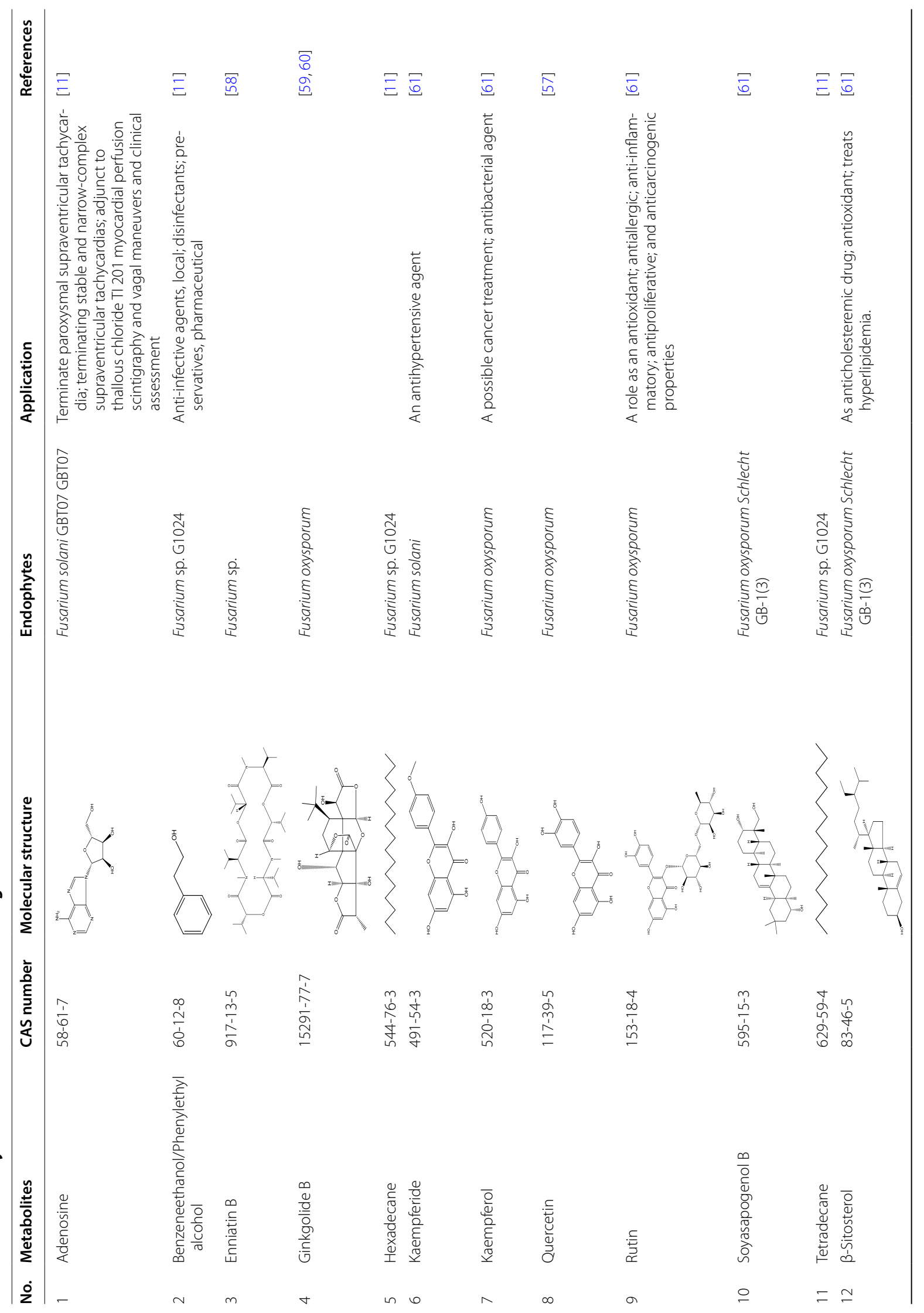




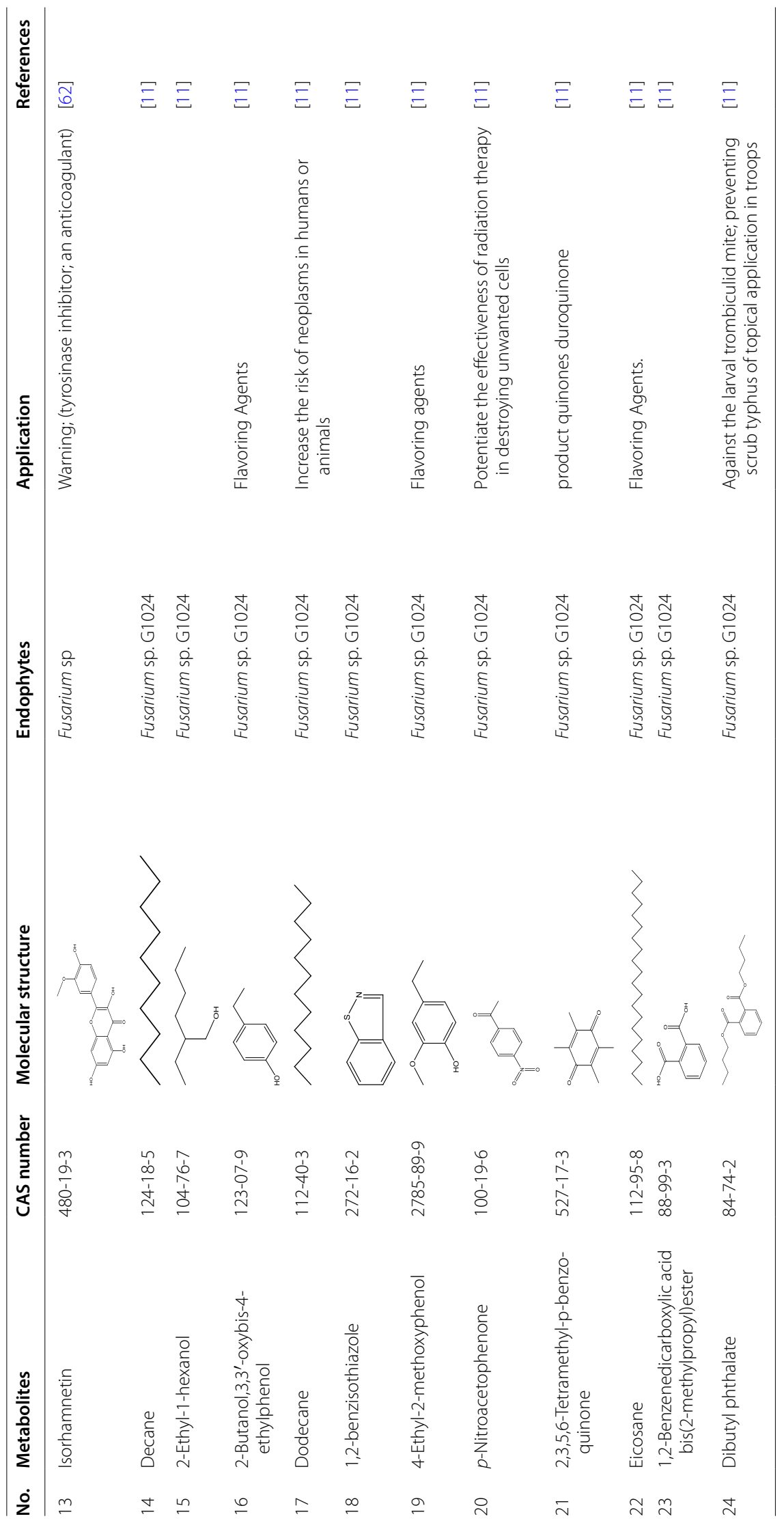




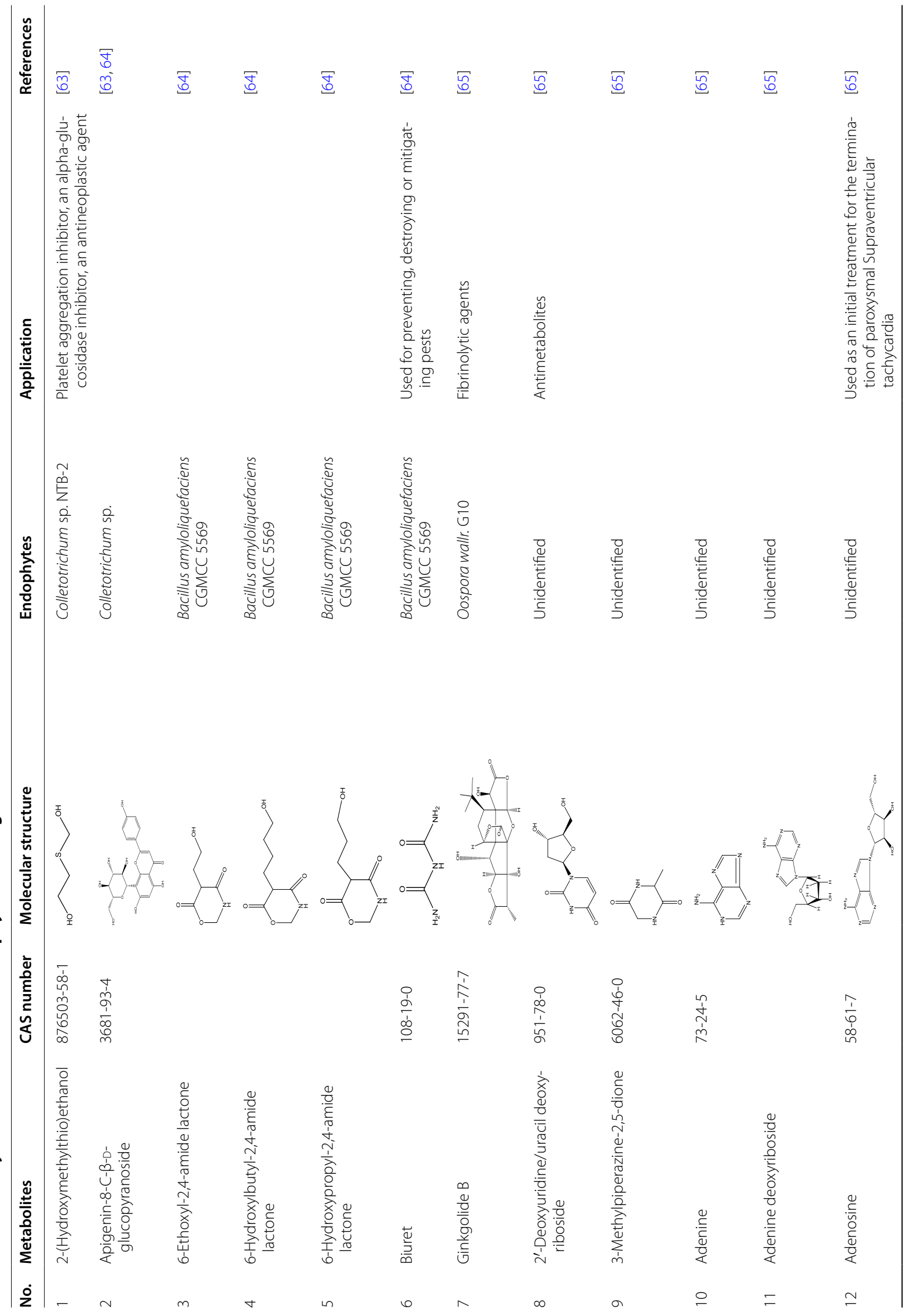




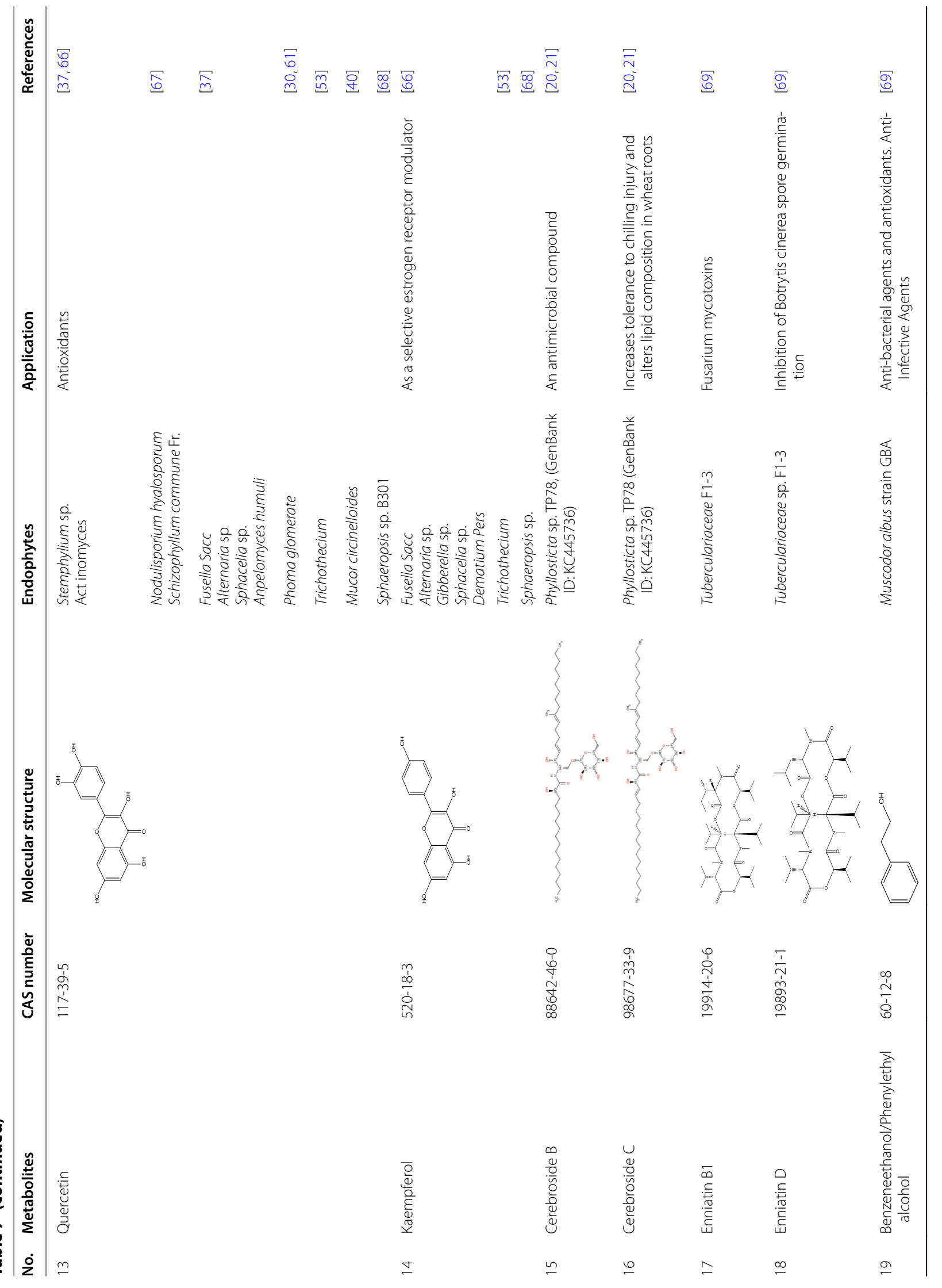




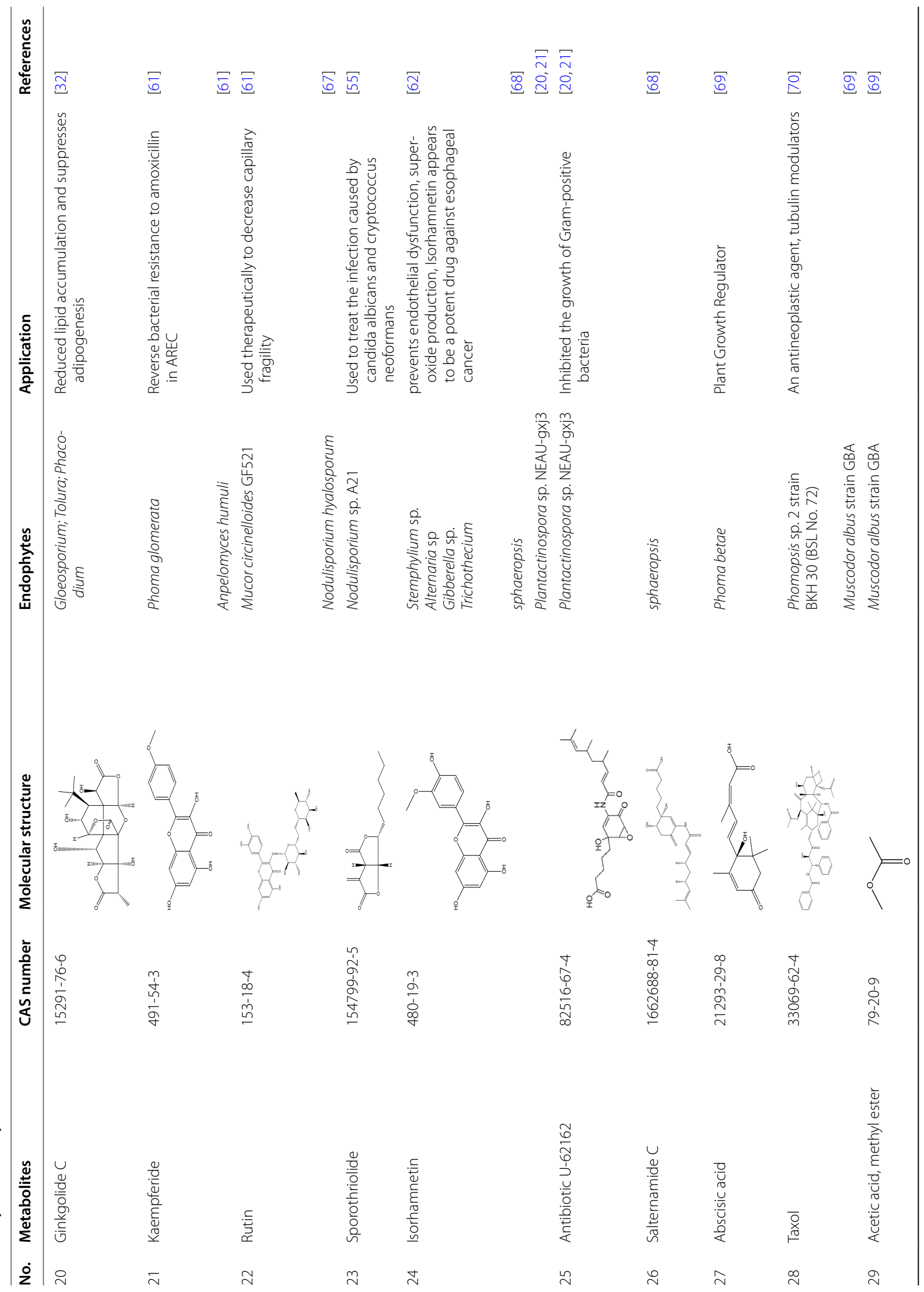




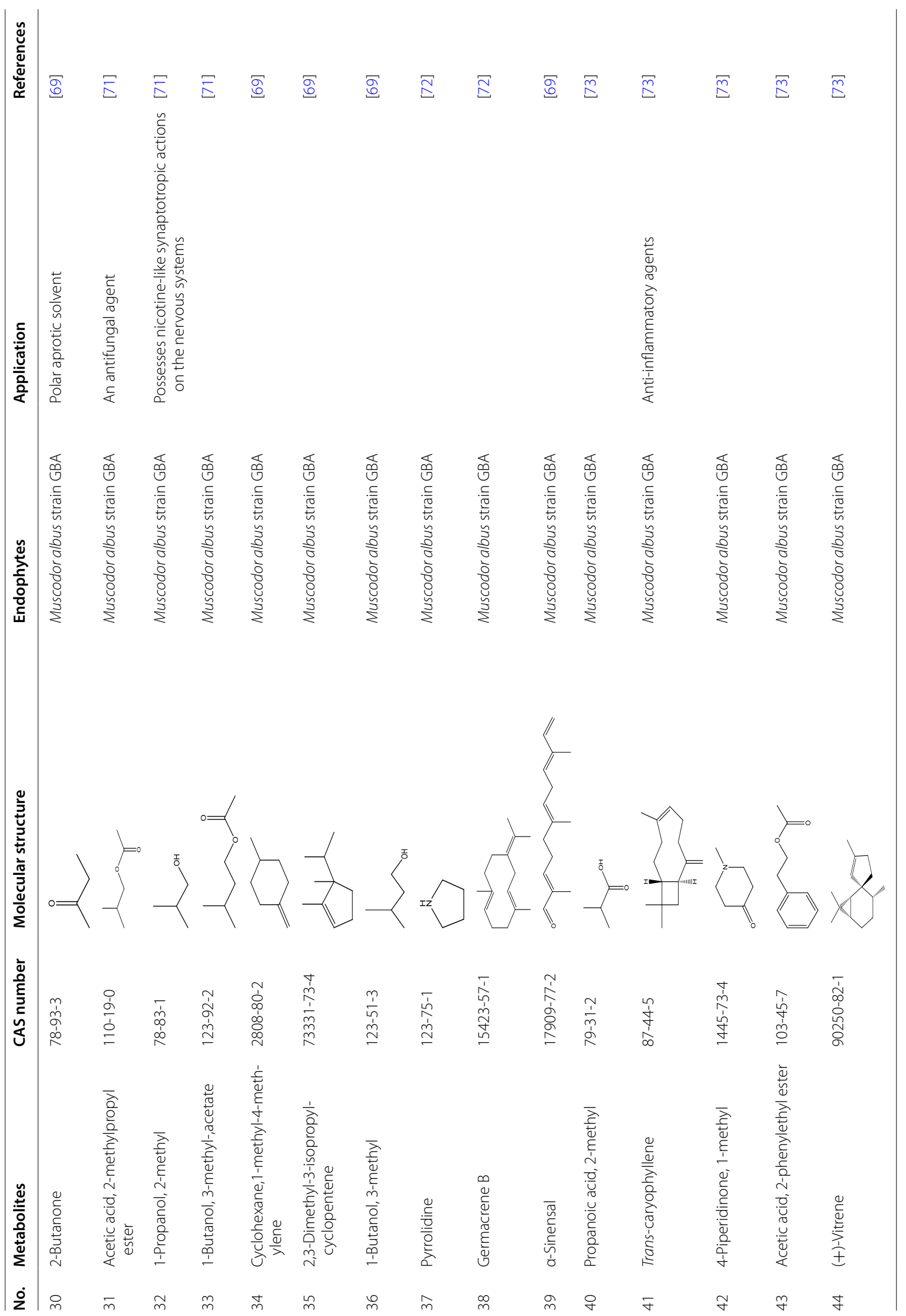


This strain displayed the strongest antibacterial activity [35].

\section{Secondary metabolites of Xylaria}

43 kinds of compounds were isolated from the fermentation products of Xylaria in Ginkgo biloba (Table 5), in which the compound 7-amino-4-methylcoumarin was isolated from the fermentation product of Xylaria sp. YX-28 [36]. It has antibacterial activity and also has strong inhibitory activity against 13 kinds of human susceptible pathogens, which is significantly higher than the positive controls ampicillin, gentamicin and tetracycline.

\section{Secondary metabolites of Fusarium}

Fusarium is one of the dominant bacteria, which can be isolated from different parts of Ginkgo cultivated in various areas. According to the literatures, 25 kinds of compounds were isolated from the fermentation products of Fusarium (Table 6). Since Fusarium of G. biloba can produce ginkgolides $B$, it can be used as a new source of ginkgolides B [37]. Some studies have shown that Fusarium oxysporum GF521 can produce rutin and kaempferol, and the total flavonoids production of endophytic fungi is $21.10 \pm 1.30 \mathrm{mg} / \mathrm{L}$, which indicates that Fusarium genus also have a high ability of producing flavonoids [37].

\section{Secondary metabolites of other genus}

53 compounds were isolated from the fermentation products of other genus in G. biloba (Table 7), some of which can also produce other valuable compounds. From the endophytic Muscodor albus GBA, 19 kinds of volatile components can be separated [24], which normally have a strong ecological effect. Some volatile components can inhibit the pathogenic microorganisms and enhance the disease resistance of plants. Bacillus amyloliquefaciens can produce 8 kinds of compounds $[35,37]$ which have some biological activities. Two compounds, apigenin-8-C-glucoside and 2-(Hydroxymethylthio) ethanol, were isolated from Colletotrichum sp. NTB-2., in which apigenin-8-Cglucoside has strong inhibitory activity against Bacillus subtilis, Salmonella typhimurium and Pseudomonas cepacia [38]. Moreover, Colletotrichum sp. could produce flavones which exhibited potent anti-cancer, antiHIV [39] and antioxidant activities [40].

In recent years, some new ginkgo endophytes and secondary metabolites have been discovered. Guo et al. [20, 21] discovered a new amide compound from Plantactinospora sp. NEAU-gxj3, Cao et al. [22] found the metabolite sporothriolide from the Nodulisporium of G. biloba, which has anti-phytopathogenic activity.

\section{Application of secondary metabolites from Ginkgo biloba}

Following the discovery by Schwabe of Germany that Ginkgo biloba contains active ingredients-ginkgo flavonoids and ginkgolides for the prevention and treatment of cardiovascular, cerebrovascular and neurological diseases, the researches about ginkgo has become more popular. Germany and France were the first countries in the world to develop ginkgo leaf products. In the mid1970s, they first developed Ginkgo biloba leaves for the treatment of cardiovascular diseases. Since then, there are more than 50 kinds of ginkgo products on the market.

In the application, Ginkgo can be used with the extracts. Some examples, a substance EGb 761 extracted from Ginkgo biloba has shown to be effective against Noise-induced hearing loss (NIHL) in an animal model. This substance is assumed to protect the cochlea from hair cell loss after intensive noise exposure by reducing reactive oxygen species (ROS). Further effects of EGb 761 on the cellular and systemic levels of the nervous system make it a promising candidate not only for protection against NIHL but also for its secondary comorbidities like tinnitus [41]; One Ginkgo biloba extract (GbE) was used as a nontoxic natural reducing and stabilizing agent for preparing cytocompatible graphene. The as-prepared GbE-reduced graphene oxide (Gb-rGO) showed significant biocompatibility with cancer cells. Addition of GbE makes rGO producing procedure cost-effective and green. This method could be used for various biomedical applications, such as tissue engineering, drug delivery, biosensing, and molecular imaging [42].

Some application has been using a part of the plant. Another example, Ginkgo tea is a kind of health food produced from Ginkgo biloba leaves. Two kinds of glycosidase were used to improve the flavor of Ginkgo tea, and three kinds of bioactivities were selected to investigate the health care function of the tea infusion [43].

The Ginkgo preparation mainly includes capsules, tablets, granules, tea bags. Capsules and tablets are most popular in the formulation of the product. Recently, new preparation like shampoo, facial cleanser and hair moisturizer have been introduced in cosmetics applications. Most of the ginkgo products on the market are registered as health foods and a few are registered as over-the-counter drugs.

In many existing products, especially in the medicines, $24 \%$ of total flavonoids and $6 \%$ of ginkgolides are the basic quality requirements for Ginkgo biloba extracts. Some famous manufacturers proposed higher standards. They appended ginkgolides A, B, C, J and biloba lactone as the quality indicators and generally required the content of ginkgolides A, B, C, J greater than $2.5 \%$, the content of biloba lactone greater than $2.6 \%$. 


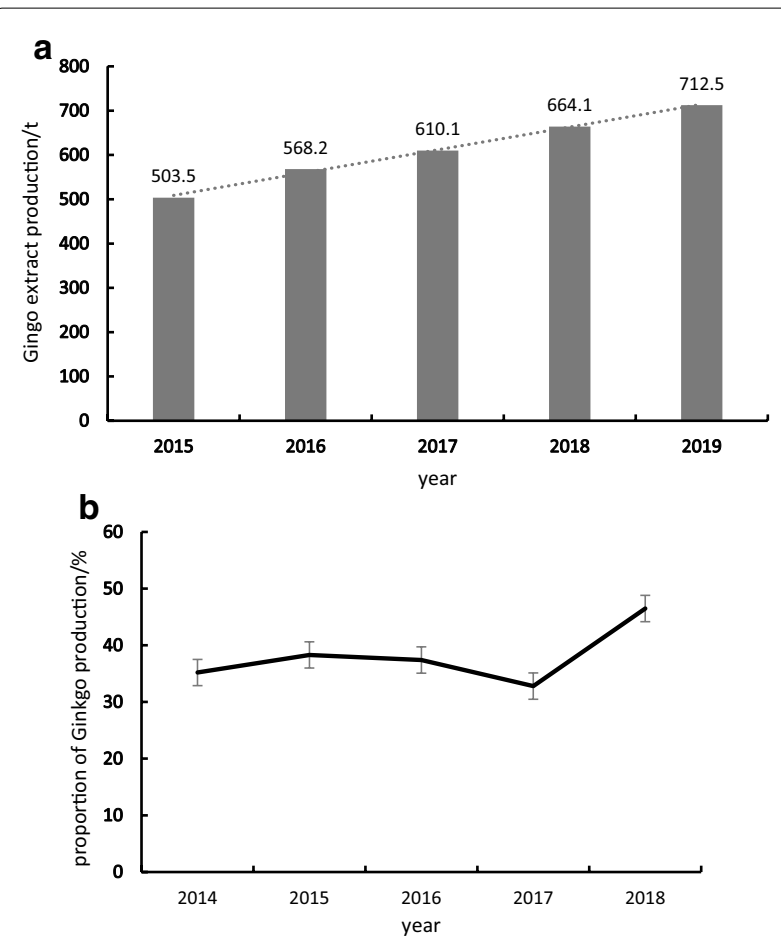

Fig. 7 The production of Ginkgo extracts in China and its proportion in the world market. a The production of Ginkgo extracts in China from 2015 to 2019; $\mathbf{b}$ the proportion of China Ginkgo products in the world market from 2014 to 2018

On the basis of data about the endophytes and secondary metabolites in G. biloba, the catalogue is diverse in terms of structural complexity and lots of them have promising biological activities, which have the potential to be a source of new pharmaceutical agents which have a constant, critical need to combat cancers, viral infections, infectious diseases, and autoimmune disorders. There is also a growing need to fight insect-borne diseases of both animals and plants as climatological changes provide conditions conducive to more intensive outbreaks of these events. The fight against any disease is a dynamic equilibrium between advances in chemotherapy and natural selection in infectious or invasive agents. If the scientific community is to maintain parity in this never-ending struggle, then new sources of novel, bioactive chemotherapeutic agents must be found.

It appears that the mechanism by which endophytes produce secondary metabolites that mimic those produced by their host plants is far from clear. Even though efforts to unravel the pathway genes in the endophytes, it has failed to detect critical genes corresponding to those existing in plants, our understanding of the mechanisms associated with the development of different diseases increases, our ability to use this knowledge to select for ever more potent and selective compounds should increase commensurately. Endophytes of G. biloba will continue to provide a fertile arena for these quests.

\section{Prospects}

With human aging process is accelerating, it has been common pursuit for a healthy and high-quality living. Since Ginkgo biloba preparations have a worldwide reputation as natural medicines and healthy products, Ginkgo development and the prospects are attractive. In the United States, Ginkgo biloba extracts have been on the list of imported drugs. Ginkgo products on the market are almost all products of American companies, and few products have been seen in Europe. At present, the European market is basically occupied by French and German products. Most of the Ginkgo extracts on the US market are produced by Japan and South Korea, a small portion is purchased from China.

Although comparing with the developed countries, China market is not competitive and too weak to take the risks, the potential of China's Ginkgo development is still worth looking forward to. China is the birthplace and main producing area of the world's Ginkgo. Many excellent Ginkgo germplasm resources are valuable treasures for China. With the sharp increase in Ginkgo resources and products output in China, the market has become more concerned at present (Fig. 7). At present, the Ginkgo products in China have low added-value and quality. In the development of ginkgo industry in China, it is necessary to increase the quality standardization and to improve the scientific research efforts and the production technology of Ginkgo preparations. It deserves to initiate new and technological products on flavonoids, bilobalide, polyisoprene, etc. Especially some new application in other industries should be explored, such as supplying in cytocompatible graphene preparation.

Chinese people have a tradition to have Ginkgo preparation as healthy products. China's population accounts for about a quarter of the world's total population. Therefore, the Ginkgo products in China should have more concerns on the domestic market and at the same time expand the international market with high-quality and featured products.

\section{Abbreviations \\ G. biloba: Ginkgo biloba; CD: electronic circular dichroism; Gb-rGO: gbE- reduced graphene oxide; NIHL: noise-induced hearing loss; ROS: reactive oxygen species.}

\section{Acknowledgements}

Not applicable.

\section{Authors' contributions}

$\mathrm{ZY}$ and $\mathrm{YT}$ drafted the manuscript and prepared tables and figures. $\mathrm{FH}$ and $\mathrm{HZ}$ contributed to revisions of the manuscript. All authors read and approved the final manuscript. 


\section{Funding}

The work reported in the paper has been supported by the National Natural Science Foundation of China (No. 31741109), the Hunan Provincial Natural Science Foundation of China (Nos. 2018JJ2145, 2018JJ2146) and the Scientific Research Project of Hunan University of Science and Technology (17XKY002, 17XKY011, 17XKY012)

\section{Availability of data and materials}

Not applicable.

\section{Ethics approval and consent to participate}

Not applicable.

\section{Consent for publication}

Not applicable.

\section{Competing interests}

The authors declare that they have no competing interests.

\section{Author details}

${ }^{1}$ College of Bioscience and Biotechnology, Hunan Agricultural University, Changsha 410128, China. ${ }^{2}$ Hunan Provincial Engineering Research Center for Ginkgo Biloba, Yongzhou 425199, China. ${ }^{3}$ College of Chemistry and Bioengineering, Hunan University of Science and Engineering, Yongzhou 425199, China.

Received: 14 July 2019 Accepted: 23 October 2019 Published online: 08 November 2019

\section{References}

1. Tan RX, Zou WX. Endophytes: a rich source of functional metabolites. Nat Prod Rep. 2001;18:448-59.

2. Saikkonen K, Wali P, Helander M, Faeth SH. Evolution of endophyteplant symbioses. Trends Plant Sci. 2004;9:275-80.

3. Nisa H, Kamili AN, Nawchoo IA, Shafi S, Shameem N, Bandh SA. Fungal endophytes as prolific source of phytochemicals and other bioactive natural products: a review. Microb Pathog. 2015;82:50-9.

4. Caruso M, Colombo AL, Fedeli L, Pavesi A, Quaroni S, Saracchi M. Isolation of endophytic fungi and actinomycetes taxane producers. Ann Microbiol. 2000;50:3-13.

5. Zhang Y, Mu J, Feng Y, Kang Y, Zhang J, Gu PJ. Broad-spectrum antimicrobial epiphytic and endophytic fungi from marine organisms: isolation, bioassay and taxonomy. Mar Drugs. 2009;7:97-112.

6. Stierle A, Strobel G, Stierle D. Taxol and taxane production by Taxomyces andreanae, an endophytic fungus of pacific yew. Science. 1993;260:214-6.

7. Lin X, Lu CH, Huang YJ, Zheng ZH, Su WJ, Shen YM. Endophytic fungi from a pharmaceutical plant, Camptotheca acuminata: isolation, identification and bioactivity. World J Microbiol Biotechnol. 2007;23:1037-40.

8. Ganley RJ, Brunsfeld SJ, Newcombe G. A community of unknown, endophytic fungi in western white pine. Proc Natl Acad Sci. 2004;101:10107-12

9. Claire J, Rob J, Rentenaar LL, Sylvain B. Enterobacteriaceae. In: Infectious diseases. 4th ed. 2017; p. 1565-78.

10. Cui Y, Yi D, Bai X, Sun B, Zhao Y, Zhang Y. Ginkgolide B produced endophytic fungus (Fusarium oxysporum) isolated from Ginkgo biloba. Fitoterapia. 2012:83:913-20.

11. Balkwill DL, Fredrickson JK, Romine MF. Sphingomonas and related genera. In: Dworkin M, et al., editors. The prokaryotes, a handbook of the biology of bacteria. New York: Springer-Verlag; 2006.

12. Huh H, Staba E, Singh J. Supercritical fluid chromatographic analysis of polyprenols in Ginkgo biloba L. J Chromatography A. 1992;600:364-9.

13. Kang SS, Kim JS, Kwak WJ, Kim KH. Flavonoids from the leaves of Ginkgo biloba. Korean J Pharmacogn. 1990;21:111-20.

14. Garrity GM, Brenner DJ, Krieg NR, Staley JT. The Proteobacteria, part C: the alpha-, beta-, delta-, and epsilonproteobacteria. In: Bergey's Manual of systematic bacteriology (ed), Springer, New York. 2005.

15. Donovan PK, Ian RM, Ann PW. The family Methylobacteriaceae. Prokaryotes. 2014;11:313-40
16. Cao YR, Wang W, Jin RX, Tang SK, Jiang Y, He WX, Lai HX, Xu LH, Jiang CL. Methylobacterium soli sp. nov. a methanol-utilizing bacterium isolated from the forest soil. Antonie Van Leeuwen. 2011;99:629-34

17. Ariyawansa HA, Thambugala KM, Manamgoda DS, Jayawardena $R$, Camporesi E, Boonmee S, Wanasinghe DN, Phookamsak R, Singang H, Singtripop C, Chukeatirote E, Kang JC, Gareth EBJ, Kevin DH. Towards a natural classification and backbone tree for Pleosporaceae. Fung Divers. 2015;71:85-139.

18. Cannon PF, Kirk PM. Fungal families of the world. Wallingford: CABI; 2007.

19. Phookamsak R, Liu JK, McKenzie EHC, Manamgoda DS, Ariyawansa HA, Thambugala KM, Dai DQ, Camporesi E, Chukeatirote E, Wijayawardene NN, Bahkali AH, Mortimer PE, Xu JC, Hyde KD. Revision of Phaeosphaeriaceae. Fungal Diversity. 2014;68:159-238.

20. Tang AM, Jeewon R, Hyde KD. A re-evaluation of the evolutionary relationships within the Xylariaceae based on ribosomal and protein-coding gene sequences. Fungal Diversity. 2009:34:127-55.

21. Guo XW, Zhang J, Li JS. A new amide metabolite from endophytic Plantactinospora sp. NEAU-gxj3. Nat Prod Res Dev. 2016;28:481-5.

22. Xue M, Zhang Q, Gao JM, Li H, Tian JM, Pescitelli G. Chaetoglobosin Vb from endophytic Chaetomium globosum: absolute configuration of chaetoglobosins. Chirality. 2012;24(8):668-74.

23. Laurain D, Trémouillaux-Guiller J, Chénieux JC, Beek TA. Production of ginkgolide and bilobalide in transformed and gametophyte derived cell cultures of Ginkgo biloba. Phytochemistry. 1997;46:127-30.

24. Zen Z, Zhu J, Chen L, Wen W, Yu R. Biosynthesis pathways of ginkgolides. Pharmacogn Rev. 2013;7:47-52.

25. Wang D, Zhang Y, Li X, Pan H, Chang M, Zheng T, Sun J, Qiu D, Zhang M, Wei D, Qin J. Potential allelopathic azaphilones produced by the endophytic Chaetomium globosum TY1 inhabited in Ginkgo biloba using the one strain-many compounds method. Nat Prod Res. 2017;31:724-8.

26. Xue M, Zhang Q, Gao JM, Li H, Tian JM, Pescitelli G. Chaetoglobosin Vb from endophytic Chaetomium globosum: absolute configuration of chaetoglobosins. Chirality. 2012;24:668-74.

27. Lindequist $U$, Lesnau A, Teuscher E, Pilgrim H. Antiviral activity of ergosterol peroxide. Pharmazie. 1989:44:579-80.

28. Zhang GZ. Identification of physiological races of S. turcicum and the biocontrol effect of Chaetomium. Changchun: Jilin University; 2012.

29. Guo ZK, Yan T, Guo Y. p-Terphenyl and diterpenoid metabolites from endophytic Aspergillus sp. YXf3. J Nat Prod. 2012;75:15-21.

30. Ge F, Tang Y, Gong Q, Ma Q, Yang L. Comparison on antimicrobial activity of 40 endophytic fungi strains from Ginkgo biloba and preliminary analysis on ingredients with antimicrobial activity. Chin Tradit Herb Drugs. 2016:47:1554-9.

31. Guo ZK, Wang R, Huang W, Li XN, Jiang R, Tan RX, Ge HM. Aspergiloid I, an unprecedented spirolactone norditerpenoid from the plantderived endophytic fungus Aspergillus sp. YXf3. Beilstein J Org Chem. 2014:10:1701-9.

32. Yan $Z Y$, Pang $L$, Luo J. Screening of ginkgolide-producing strain from endophytic fungi in Ginkgo biloba. West Chin J Pharm Sci. 2007;22:491-3.

33. Li HQ, Li XJ, Wang YL. Antifungal metabolites from Chaetomium globosum, an endophytic fungus in Ginkgo biloba. Biochem Syst Ecol. 2011;39:876-9.

34. Liu X, Dong $M$, Chen $X$, Jiang $M, L v X$, Zhou J. Antimicrobial activity of an endophytic Xylaria sp. YX-28 and identification of its antimicrobial compound 7-amino-4-methylcoumarin. Appl Microbiol Biotechnol. 2008;78:241-7

35. Han XL, Kang JC, He J. Isolation and identification of endophytic fungi of falvonoid-producing Ginkgo biloba. J Fung Res. 2008;6:40-5.

36. Liu X, Dong M, Chen X, Jiang M, Lv X, Zhou J. Antimicrobial activity of an endophytic Xylaria sp. YX-28 and identification of its antimicrobial compound 7-amino-4-methylcoumarin. Appl Microbiol Biotechnol. 2008;78(2):241-7.

37. Zhou SL, Chen SL, Tan GH. Antibacterial substances of endophytic fungus isolated from Ginkgo biloba. Nat Prod Res Dev. 2010;22:193-6.

38. Zhang CL, Liu SP, Lin FC, Kubicek CP, Druzhinina IS. Trichoderma taxi sp. nov., an endophytic fungus from Chinese yew Taxus mairei. FEMS Microbiol Lett. 2007;270:90-6.

39. Nakanishi T, Murata H, Inatomi Y, Inada A, Murata J, Lang FA, Yamasaki $\mathrm{K}$, Nakano M, Kawahata T, Mori H, Otake T. Screening of anti-HIV-1 activity of North American plants. Anti-HIV-1 activities of plant extracts, and active components of Lethalia vulpina (L.) Hue. J Nat Med. 1998:52:521-6. 
40. Li X, Tian Y, Yang SX, Zhang YM, Qin JC. Cytotoxic azaphilone alkaloids from Chaetomium globosum TY1. Bioorg Med Chem Lett. 2013;23:2945-7.

41. Konstantin T, Sabine K, Sönke A, Holger S. Protective effects of Ginkgo biloba extract EGb 761 against noise trauma-induced hearing loss and tinnitus development. Neural Plast. 2014;2014:427298.

42. Gurunathan S, Han JW, Park JH, Eppakayala V, Kim JH. Ginkgo biloba: a natural reducing agent for the synthesis of cytocompatible graphene. Int J Nanomed. 2014;9:363-77.

43. Fang $X$, Dong $Y$, Xie Y, Wang L, Wang J, Liu Y, Zhao L, Cao F. Effects of $\beta$-glucosidase and a-rhamnosidase on the contents of flavonoids, ginkgolides, and aroma components in Ginkgo tea drink. Molecules. 2019;24(10):2009.

44. Qin JC, Zhang YM, Hu L. Cytotoxic metabolites produced by Alternaria no. 28, an endophytic fungus isolated from Ginkgo biloba. Nat Prod Commun. 2009:4:1473-6.

45. Tian Y. Identification of three Chaetomium strains and the activity of secondary metabolites. Changchun: Jilin University; 2013.

46. Yu HS. Study on the diversity and activity of endophytic fungi from Ginkgo. Chongqing: The Second Military Medical University; 2010.

47. Li H, Xiao J, Gao YQ. W globosum, an endophytic fungus in Ginkgo biloba, and their phytotoxic and cytotoxic activities. J Agric Food Chem. 2014;62:3734-41.

48. Qin JC, Gao JM, Zhang YM. Polyhydroxylated steroids from an endophytic fungus, Chaetomium globosum ZY-22 isolated from Ginkgo biloba. Steroids. 2009;74:786-90.

49. Zhang G, Zhang Y, Qin J. Antifungal metabolites produced by Chaetomium globosum, No. 04, an endophytic fungus isolated from Ginkgo biloba. Indian J Microbiol. 2013;53:175.

50. Yan ZY, Luo J, Guo XH, Zeng QQ. Screening of ginkgolides-producing endophytic fungi and optimal study on culture condition. Nat Prod Res Dev. 2007;19:554-8.

51. Yan T, Guo ZK, Jiang R. New flavonol and diterpenoids from the endophytic fungus Aspergillus sp. YXf3. Planta Med. 2013;79:348-52.

52. Zhang W, Wei W, Shi J. Natural phenolic metabolites from endophytic Aspergillus sp. IFB-YXS with antimicrobial activity. Bioorg Med Chem Lett. 2015;25:2698-701.

53. Qin JC, Zhang YM, Gao JM. Bioactive metabolites produced by Chaetomium globosum, an endophytic fungus isolated from Ginkgo biloba. Bioorg Med Chem Lett. 2009;19:1572-4.

54. Wang GP, Wang LW, Zhang YL. Identification of an endophytic fungus of Ginkgo biloba TMSF169 and its antifungal metabolites. Chin J Biol Control. 2012;28:226-34

55. Liu JJ, Chen SJ, Gong HX. An endophytic fungus producing orange pigment isolated. Prog Modern Biomed. 2009;9:246-50.

56. Wu YY, Zhang TY, Zhang MY, Cheng J, Zhang YX. An endophytic Fungi of Ginkgo biloba L. produces antimicrobial metabolites as potential inhibitors of FtsZ of Staphylococcus aureus. Fitoterapia. 2018;128:265-71.

57. Ju XY, Feng YJ, Chen FM. Volatile constituents and their fibrinolytic activity of endophytic fungus Fusarium sp. Gl024 from Ginkgo biloba. Microbiology. 2006;33:8-11.

58. Yi DW, Zhang YX, He YJ. Fermentation metabolites of endophytic fungus isolated from Ginkgo biloba. J Microb. 2007;27:102-6.
59. Qian L, Yang MF, Ran XQ. Isolation and identification of endophytic fungi producing flavonoids from Ginkgo biloba L. J Mt Agric Biol. 2007:26:305-10.

60. Zhao QY, Fan MT, Shi JL. Isolation and identification of flavonesforming endophytes from Ginkgo biloba L. Acta Agric Bor Occid Sin. 2007;16:169-73.

61. Zhao SS, Zhang YY, Yan W, Cao LL, Xiao Y, Ye YH. Chaetomium globosum CDW7, a potential biological control strain and its antifungal metabolites. FEMS Microbiol Lett. 2017;364:fnw287.

62. Zhou SL, Zhou SL, Wang MX. Two compounds from the endophytic Colletotrichum sp. of Ginkgo biloba. Nat Prod Commun. 2011;6:1131-2.

63. Bao F, Fan MT, He J. The isolation and screening of ginkgolide B-producing endophytic fungi. Acta Agric Bor Occid Sin. 2008;17:328-31.

64. Zhao QY, Fan MT, Shi JL. Isolation of endophytes from Ginkgo biloba plants and screening of flavonoid-producing strains. Trans Chin Soc Agric Mach. 2007;38:199-201.

65. Gao JH, Yi DW, Zhou Y. Studies on isolation and identification of antibiotic substances from a strain of endophytic fungus of Ginkgo biloba L. Chin J Antibiot. 2015;40:728-31.

66. Zhao W, Li L, Wang Z, Wang Z, Gao X, Yu M. Isolation and product identification of a flavonid-producing endophytic fungus. J Microbiol. 2008:28:88-91.

67. Hao G, Du X, Zhao F, Ji H. Fungal endophytes-induced abscisic acid is required for flavonoid accumulation in suspension cells of Ginkgo biloba. Biotechnol Lett. 2010;32:305-14.

68. Banerjee D, Strobel G, Geary B. Muscodor albus strain GBA, an endophytic fungus of Ginkgo biloba from United States of America, produces volatile antimicrobials. Mycology. 2010;1:179-86.

69. Kumaran RS, Choi YK, Lee S. Isolation of taxol, an anticancer drug produced by the endophytic fungus, Phoma betae. Afr J Biotechnol. 2012:11:950-60.

70. Kumaran RS, Hur BK. Screening of species of the endophytic fungus Phomopsis for the production of the anticancer drug taxol. Biotechnol Appl Biochem. 2009;54:21-30.

71. Deng BW, Liu KH, Chen WQ, Ding XW, Xie XC. Fusarium solani, Tax-3, a new endophytic taxol-producing fungus from Taxus chinensis. World J Microbiol Biotechnol. 2009;25:139-43.

72. Liu KH, Ding XW, Deng BW, Chen WQ. Isolation and characterization of endophytic taxol-producing fungi from Taxus chinensis. J Ind Microbiol Biotechnol. 2009;36:1171-7.

73. Tang X, Zhu JH. Research for isolation and cultivation of flavone-producing endophytes from Ginkgo biloba. L. J Ningbo Polytech. 2010;14:96-101.

\section{Publisher's Note}

Springer Nature remains neutral with regard to jurisdictional claims in published maps and institutional affiliations.

Ready to submit your research? Choose BMC and benefit from

- fast, convenient online submission

- thorough peer review by experienced researchers in your field

- rapid publication on acceptance

- support for research data, including large and complex data types

- gold Open Access which fosters wider collaboration and increased citations

- maximum visibility for your research: over 100M website views per year

At BMC, research is always in progress.

Learn more biomedcentral.com/submissions 